\title{
MicroRNAs as Potential Biomarkers for Exercise-Based Cancer Rehabilitation in Cancer Survivors
}

\author{
Yanping Jiang (D), Kulsoom Ghias, Sanjeev Gupta (D) and Ananya Gupta *(D) \\ Department of Physiology, National University of Ireland, H91 TK33 Galway, Ireland; \\ Y.Jiang7@nuigalway.ie (Y.J.); k.ghias1@nuigalway.ie (K.G.); sanjeev.gupta@nuigalway.ie (S.G.) \\ * Correspondence: ananya.gupta@nuigalway.ie
}

Citation: Jiang, Y.; Ghias, K.; Gupta, S.; Gupta, A. MicroRNAs as Potential Biomarkers for Exercise-Based Cancer Rehabilitation in Cancer Survivors.

Life 2021, 11, 1439. https:/ /

doi.org/10.3390/life11121439

Academic Editor: Bruce J. Nicholson

Received: 11 November 2021

Accepted: 14 December 2021

Published: 20 December 2021

Publisher's Note: MDPI stays neutral with regard to jurisdictional claims in published maps and institutional affiliations.

Copyright: (c) 2021 by the authors. Licensee MDPI, Basel, Switzerland. This article is an open access article distributed under the terms and conditions of the Creative Commons Attribution (CC BY) license (https:// creativecommons.org/licenses/by/ $4.0 /)$.

\begin{abstract}
Expression and functions of microRNAs (miRNAs) have been widely investigated in cancer treatment-induced complications and as a response to physical activity, respectively, but few studies focus on the application of miRNAs as biomarkers in exercise-based cancer rehabilitation. Research has shown that certain miRNA expression is altered substantially due to tissue damage caused by cancer treatment and chronic inflammation. MiRNAs are released from the damaged tissue and can be easily detected in blood plasma. Levels of the miRNA present in peripheral circulation can therefore be used to measure the extent of tissue damage. Moreover, damage to tissues such as cardiac and skeletal muscle significantly affects the individual's health-related fitness, which can be determined using physiologic functional assessments. These physiologic parameters are a measure of tissue health and function and can therefore be correlated with the levels of circulating miRNAs. In this paper, we reviewed miRNAs whose expression is altered during cancer treatment and may correlate to physiological, physical, and psychological changes that significantly impact the quality of life of cancer survivors and their role in response to physical activity. We aim to identify potential miRNAs that can not only be used for monitoring changes that occur in health-related fitness during cancer treatment but can also be used to evaluate response to exercise-based rehabilitation and monitor individual progress through the rehabilitation programme.
\end{abstract}

Keywords: miRNA; cancer survivorship care; rehabilitation; personalized exercise intervention; molecular biomarker

\section{Rehabilitation in Cancer Survivors}

It is estimated that there were 18.1 million newly diagnosed cancer cases and 9.6 million cancer-related deaths globally in 2018 [1]. Despite the advances in cancer treatment, cancer incidence and mortality have been increasing over the years, thus making cancer one of the greatest health threats to human beings [2]. Cancer treatment strategies, such as surgery, chemotherapy, and radiotherapy, increase survival and prolong the lifespan of cancer survivors. However, these strategies have many adverse effects on patients' health-related fitness (including cardiovascular endurance, muscular strength, muscular endurance, flexibility, body composition). Evidence suggests patients recovering from cancer have an increased risk of developing myriad chronic, comorbid conditions, such as metabolic syndrome, fatigue, muscle wasting (sarcopenia/cachexia), bone loss, lymphoedema, cardiotoxicity, and mental health issues, and respond poorly to standard treatment, which makes it challenging to treat such conditions [3-7]. The risk of developing long-term side effects following cancer treatment is influenced by: age at diagnosis; comorbidities; cancer type and stage; and treatment type, dose, and duration [7]. Additionally, these side effects not only occur during treatment but can emerge many years after the completion of treatment. This, in turn, leads to a long-term illness burden and morbidity and an increased risk of premature mortality $[4,5]$. Therefore, the importance of addressing the long-term needs of cancer survivors is well-recognised [8]. 
According to the National Cancer Registry Ireland (NCRI), 22,640 patients are newly diagnosed with cancer every year in Ireland [4]. Cancer survivorship begins at the time of diagnosis and continues until the end of life and is broadly referred to as 'living with and beyond cancer' [4]. With improvements in cancer treatment, the survival rate has improved significantly, and, for most cancers, is estimated to be $77-98 \%$ at one year and $63-92 \%$ at five years posttreatment. There were 173,000 cancer survivors living in Ireland in 2016, and this number is predicted to exceed 200,000 in 2020 [5]. The National Cancer Strategy Ireland 2017-2026 [4] outlined the need to establish support services providing effective management of posttreatment health issues to improve the quality of life (QoL) of cancer survivors. The development of such a service has been hindered by a lack of research and information defining the posttreatment needs of cancer patients. In this regard, great efforts should be directed to develop rehabilitation strategies based on cancer survivors needs to reduce or alleviate cancer treatment-induced complications.

Exercise-based cancer rehabilitation is one of these strategies and has been proved to be an effective way to improve the QoL in cancer survivors. There are three main types of exercise training included as part of cancer rehabilitation: resistance exercise, aerobic exercise, and the combination of both [9]. Flexibility and mobility exercises aiming to restore the normal range of motion also plays an integral part in cancer rehabilitation. Recent studies have overwhelmingly supported that exercise-based cancer rehabilitation programs can alleviate, prevent, and even treat the side effects caused by cancer treatment. A randomized controlled trial from overweight or obese breast cancer survivors showed that, when compared with usual care, participants who received 16 weeks of combined aerobic and resistance exercise intervention had physiologically improved metabolic syndrome z-score, sarcopenic obesity, and circulating biomarkers, such as insulin, insulin-like growth factor-1 (IGF-1), leptin, and adiponectin [10]. In non-small cell lung cancer patients, after initial surgical resection, 8-week combined aerobic exercise and high-intensity respiratory muscle training can significantly improve peak oxygen uptake $\left(\mathrm{VO}_{2}\right.$ peak), exercise capacity, and respiratory muscle strength [11]. Breast cancer patients who received adjuvant chemotherapy were more susceptible to develop sarcopenia and dynapenia. While these symptoms can be reversed by resistance exercise training undertaken during and after treatment, such reversal was correlated to a significant improvement of the long-term outcome of breast cancer survivors [12]. In a systematic review of 16 trials with cancer patients undergoing treatment, physical exercise was reported to generate better effects than usual care, especially on maintaining muscle mass and strength [9]. Despite not very strong evidence, resistance exercise seems to be more effective than aerobic exercise both on muscle mass and strength, which was consistent with the findings of Courneya et al. [13]. In addition, cancer patients who received exercise intervention had reduced depressive symptoms and improved emotional functions as well as QoL compared to their counterparts [11,14-16]. Taken together, exercise-based cancer rehabilitation contributes significantly to the improvement of the QoL of cancer survivors by improving health-related fitness and physical function.

In addition to a supervised exercise programme, home-based exercise also showed promising prospects in cancer rehabilitation. A multicentre randomized controlled trial suggested that home-based physical activity consisted of combined endurance (same as aerobic exercise) and resistance training during 27 weeks significantly increased $\mathrm{VO}_{2}$ peak compared to a decrease in the usual care group [17]. In addition to endurance and resistance exercise, home-based walking training was also reported to benefit breast cancer patients for cardiorespiratory fitness [18]. These results aligned with the hospital-based rehabilitation programs, revealing that home-based physical activity was favourable to cancer patients under adjuvant or neoadjuvant chemotherapy $[19,20]$. Moreover, this kind of homebased rehabilitation program was of great feasibility and practicality if patients were well instructed. In summary, exercise-based cancer rehabilitation is beneficial to cancer survivors regardless of the type and place. Therefore, a properly structured exercise-based rehabilitation programme is an unmet need for cancer patients undergoing treatment. 


\section{Introduction to miRNAs}

miRNAs are short, 20-22-nucleotide, noncoding RNAs that inhibit the expression of their cognate target genes by directly binding to their mRNAs, thus blocking their translation and targeting them for degradation. In this way, miRNAs play an essential part in regulating gene expression in cells. Various studies have elucidated that the aberrant expression of miRNAs is associated with the onset and progress of multiple diseases, including cancer, diabetes, inflammation, cardiovascular disease, neurological disorders, etc. Evidence has also shown that miRNAs can act as intracellular modulators of responses to cancer treatment and treatment-induced complications or toxicities [21,22]. MiRNAs have been attributed with several characteristics such as (1) presence in multiple body fluids, including blood; (2) high stability; (3) resistance to RNA enzyme, thus resulting in long half-life; (4) tissue-specific function; and (5) easy detection and quantitation by different methods. These properties make miRNAs amenable to a wide range of applications in diagnosis, prognosis, and treatment in multiple disease settings.

Cells constantly secrete small vesicles $(30-150 \mathrm{~nm})$ called exosomes, which are found in abundance in all body fluids including blood. These vesicles contain RNA and protein secreted from the cells from which the exosome originates and are involved in many biological functions, including cell-to-cell communication and signalling [23,24]. Since exosomes represent a snapshot of the cellular contents, any condition that affects the normal functions of the cell is likely to alter the composition of exosomes. As a result, RNA and protein present in the exosomes can be used as biomarkers that can have both prognostic and diagnostic applications [23,24]. Consequently, profiling of circulating RNAs, in particular miRNAs, have been used in a number of studies to identify novel and highly promising biomarkers for many pathologies including neurodegenerative diseases such as Alzheimer's and Parkinson's, brain injury, presence of brain tumours, and in cancer (breast and pancreatic cancers) $[23,24]$. Many of these molecules were determined to be associated with exosomes. Exosomes can be easily purified and analysed and therefore have gained importance in research as a source for identification of novel biomarkers. For instance, miRNAs in exosomes are reported to be promising biomarkers in Alzheimer's screening and progression monitoring as well as chemoresistance and metastasis in cancer [23,24]; miR-375 and miR-9 have shown promise as prognostic biomarkers for prediabetes and Type 2 Diabetes Mellitus (T2DM) [25]; antagomiRs, the synthetic antagonists of miRNAs, could compete with the target mRNA for binding with its cognate miRNA, thus inhibiting miRNA function. This helps to inhibit miRNA-mediated suppression of gene expression and seems encouraging in various diseases as a therapeutic approach as inhibitor of miRNAs [26]; examples are shown in Table 1. 
Table 1. The application of miRNAs in diagnosis, treatment, and prognosis in cancer.

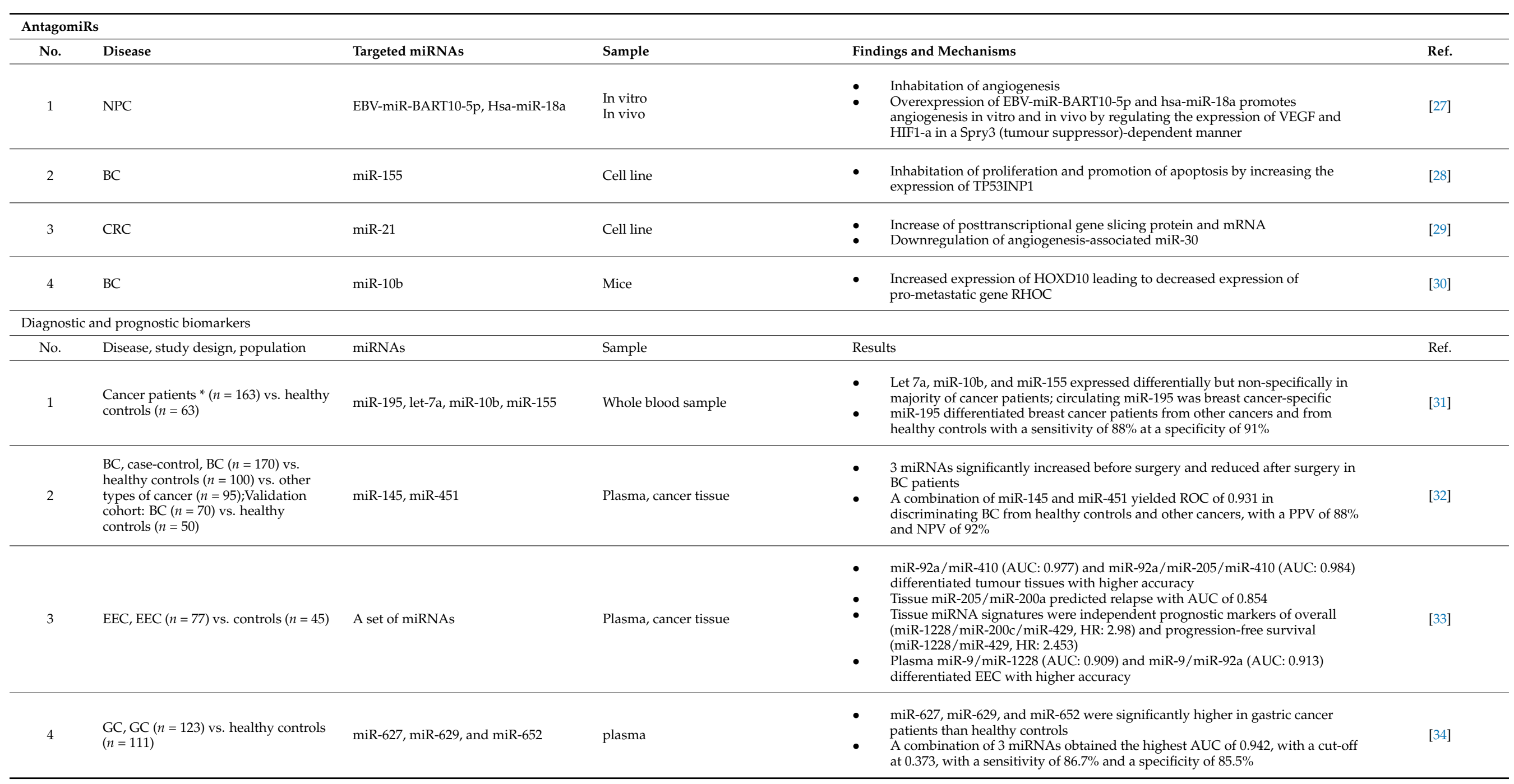

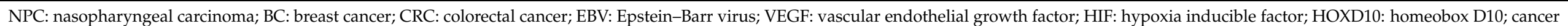
patients *: including breast, prostate, colon, and renal cancer and melanoma; NSCLCs: non-small cell lung carcinoma; EEC: endometrioid endometrial cancer; AUC: area under curve; GC: gastric cancer. 
Aberrant miRNA expression, either downregulated or upregulated in various cancer cell lines or clinical tumour tissues, can not only directly reflect chromosomal or genomic changes in cancer-related genes but also appear to have clinical significance. For example, the change in expression of these molecules has been linked to disease severity and prognosis [35]. Changes in the expression and function of certain of these miRNAs have also been related to the course of disease [35]. The researchers found that circulating miRNA levels can be used to identify serum samples from cancer patients from samples from healthy people and samples taken before and after surgery by analysing specific miRNAs in serum or blood plasma. Heneghan and colleagues found elevated miR-195 expression in 148 BC cancer patients using real-time PCR analysis. Furthermore, two weeks following breast reduction, circulating miR-195 and let-7a levels were shown to decrease in patients' blood, reaching the expression level seen in the healthy group [31]. Schooneveld and colleagues found substantial $(p<0.05)$ variations in miR-215, miR-299-5p, and miR-411 expression levels in sera samples from 20 healthy controls and 75 patients with BC, including 16 patients with untreated metastatic breast. The study revealed that miRNA expression was downregulated in malignant serum samples; however, the expression levels reverted to normal eight weeks after surgical treatment [36]. In another investigation, Enders et al. [32] found a statistically significant $(p<0.005)$ drop in plasma levels of miRNAs in 170 BC patients. The authors discovered a combination plasma biomarker of miR-451 and miR-145 that is highly effective in identifying BC patients from healthy volunteers $(p<0.0001)$. As a result, miRNAs have become a potential noninvasive tool for cancer diagnosis and prognosis.

MiRNA expression and function has also been investigated in exercise and fitness, especially in the exercise physiology of athletes [37]. For instance, miRNA is regarded as a key regulator of the signalling pathways of exercise adaptation, such as the IGF1/PI3K/AKT/ mTOR axis, and is associated with phenotypic features, such as $\mathrm{VO}_{2}$ max. Therefore, miRNA expression patterns were proposed to define responses to exercise and could also be utilized to assess physical performance and capacity through monitoring changes in physiologic parameters that determine health-related fitness [38]. Davidsen et al. [39] found $\mathrm{miR}-378$, miR-29a, and miR-26a were downregulated in low responders to resistance exercise and unchanged in high responders, whereas miR-451 was upregulated in high responders, suggesting that the specific expression pattern of miRNAs may help evaluate the responsiveness to physical activity. Domańska-Senderowska et al. [40] and Polakovičová et al. [41] also reviewed miRNAs and their roles in physical activity. In addition, due to its role in the cardiorespiratory and muscular system, miRNA has also been investigated in the rehabilitation program. For example, downregulated has-miR-125b-1-3p and upregulated has-miR-1290 were found in heart failure patients who received cardiac rehabilitation (2 weeks of bicycle ergometer and resistance exercises) [42]; miR-335-3p and miR-657, posttranscriptional regulators of IL-37 production, were increased after a rehabilitation program in sarcopenia patients, accompanied by improvement of physical and cognitive conditions [43]. These works have shown that miRNAs may be promising biomarkers for a rehabilitation program.

Although miRNAs have been widely studied in diseases and in response to physical activity (as shown in Figure 1), few studies have investigated the application of miRNAs as a dynamic monitoring tool during exercise-based cancer rehabilitation. In the following sections, we will review the relationship between miRNAs and common treatment-induced complications, namely (1) metabolic syndrome, (2) cardiorespiratory toxicity, (3) cancer cachexia, and (4) depression and anxiety. We also summarize current knowledge on how physical activity can influence these miRNAs, particularly in the exercise-based cancer rehabilitation program. Finally, we will discuss how these miRNAs can be used to predict the QoL of cancer survivors. We aim to identify potential miRNAs for future investigation to evaluate or monitor progress in exercise-based rehabilitation for cancer survivors. 


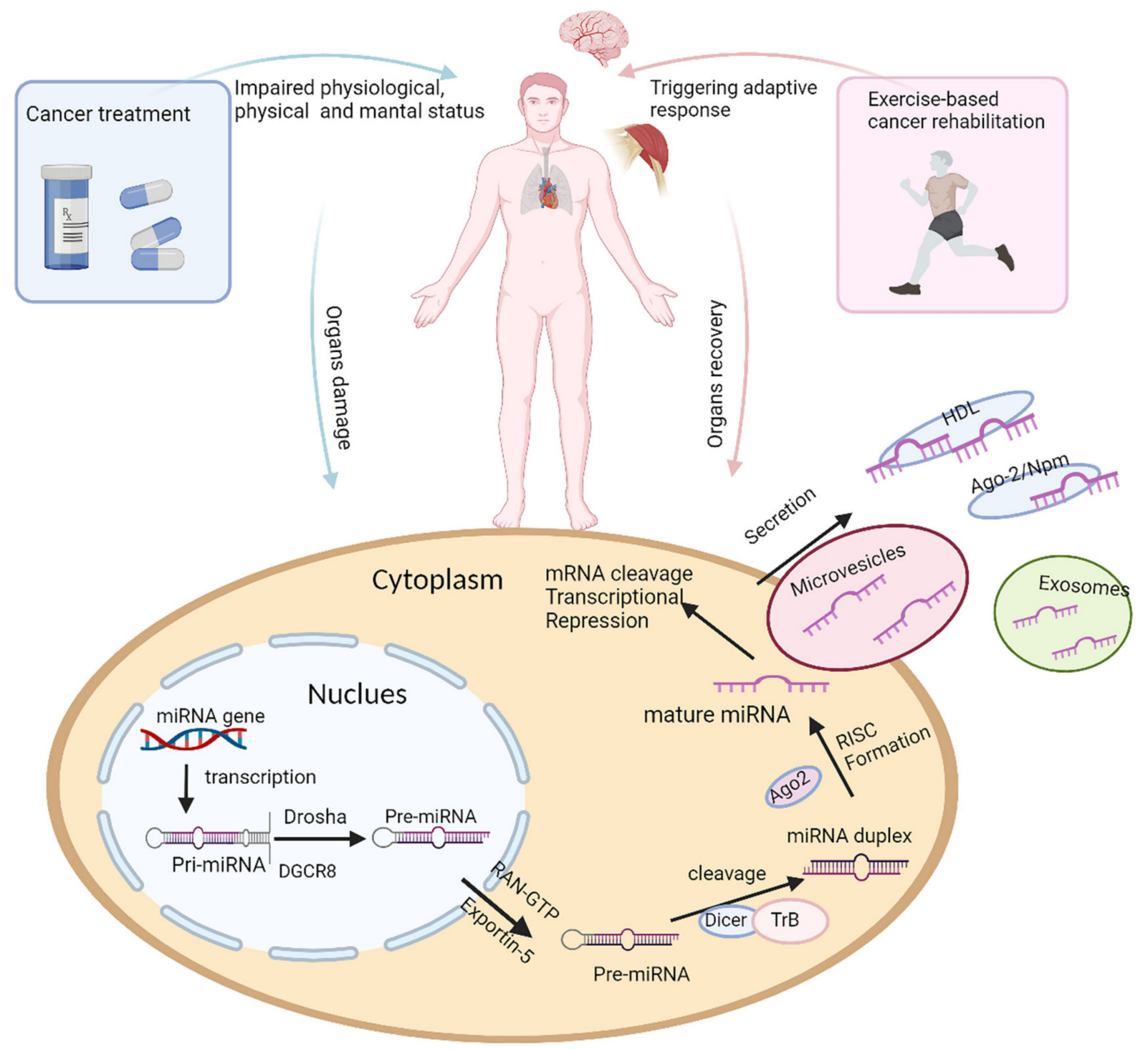

Figure 1. The impact of cancer treatment and physical activity on miRNA biogenesis. Organ damage can be caused as a result of cancer or as an adverse effect of cancer treatment, leading to decreased physical and mental ability and poor quality of life for cancer survivors, while exercise-based cancer rehabilitation triggers adaptive responses, resulting in altered miRNA expression, in damaged organs, thus promoting in organ recovery and improved quality of life. The diagram illustrates the changes in miRNA expression that can occur during tissue damage, toxicity, treatment side effects, and during physical activity, and this is part of the adaptive process or physiologic responses to exercise. During tissue damage, miRNAs may be released into circulation. miRNA biogenesis and molecular mechanisms of miRNA production can also be altered by disease or as a response to physical activity. miRNA biogenesis begins in the nucleus, where primary miRNA (pri-miRNA), transcribed by miRNA gene, is processed by Drosha and Dgcr8 into stem-looped structures, precursor miRNA (pre-miRNA). Pre-miRNA is exported by Exportin 5 into cytoplasm, where mature miRNA is produced after further processing by Dicer. Mature miRNA is transported out of cell by either exocytosis or combining protein complex, regulating gene expression in cancer treatment-induced complications or adaptive changes during exercise-based cancer rehabilitation.

\section{3. miRNAs in Cancer Treatment-Induced Complications and Physical Activity}

\subsection{Metabolic Syndrome}

Metabolic syndrome is a clustering of metabolic disorders, including insulin resistance, dyslipidaemia, and high blood pressure, which can contribute to T2DM and cardiovascular disease (CVD) [44]. Available evidence indicates that metabolic syndrome may increase the risk of common solid tumours, although the risk may differ between the sexes and ethnicity [45]. Moreover, the metabolic syndrome might be the causative link between 
cancer treatment and cardiac dysfunction in cancer survivors, as it is associated with pre-inflammatory, inflammatory, and prethrombotic effects. These responses worsen cancer-related comorbidity and mortality [46,47]. Cancer treatment itself can also lead to the development of the metabolic syndrome. Studies have shown that the risk of suffering treatment-related metabolic syndrome in cancer patients was 1.31- to 4.58-fold greater than in the control group [48,49]. Currently, three main factors contribute to cancer treatmentinduced metabolic syndrome: (1) inhibition or damage to the pituitary and hypothalamus; (2) resection or toxicity to gonadal glands and other endocrine glands; and (3) physical inactivity. These factors result in chronic hormonal disturbance and calorie imbalance, which in turn lead to obesity, insulin resistance, impaired lipid transport, impaired glucose uptake, and, eventually, to increased risk of CVD [46].

Research has shown that miRNAs are key regulators of metabolic syndrome in cancer patients. miRNA-mediated glucose metabolism and lipid metabolism dysregulation are the main manifestations of cancer treatment-induced metabolic syndrome. These miRNAs are predominantly expressed in macrophages and adipocytes and subsequently released into the systemic circulation. These miRNAs are taken up by recipient cells, such as adipocytes and hepatocytes, in which the miRNAs regulate a series of cellular processes, such as insulin secretion, insulin sensitivity, pancreas homeostasis, lipid storage, and inflammation of adipose tissue (for review, see Zhang et al. [50]). A group of miRNAs were shown to play an essential role in metabolic syndrome (for review, see Huang et al. [51] and Eckel et al. [52]) through a mechanism involving the PI3K/Akt and TGF- $\beta / S m a d 3$ signalling pathways as well as their target genes, such as PTEN, GLUT4, IRS-1 [51,52].

As physical activity and exercise training can manage weight gain and balance calories, exercise is a promising treatment strategy for cancer treatment-induced metabolic syndrome. A population-based prospective cohort study recruiting 1696 breast cancer survivors showed that regular exercise diminished the prevalence of metabolic syndrome from $55.18 \%$ at baseline to $33.14 \%$ at 60 months postdiagnosis [53]. Zhou et al. [54] recruited 209 subjects with metabolic syndrome and 234 controls to investigate the correlation between physical activity-related miRNAs and metabolic syndrome. Results showed that, among 55 miRNAs detected, only miR-197, miR-126, and miR-130a were significantly correlated to physical activity. Moreover, the expression of miR-126 and miR-130a was lower in the most active participants with the highest metabolic equivalent hours per week of physical activity (MET-h/week). In other words, individuals with the highest MET-h/week had a lower risk of metabolic syndrome. By contrast, miR-197 expression was elevated with increased physical activity or MET-h/week. However, after adjustment for age, sex, and disease settings, results showed that miR-126 significantly increased the risk of metabolic syndrome. At the same time, miR-197 decreased the risk, suggesting the correlation between physical activity and metabolic syndrome risk may partly rely on miR-126 and miR-197.

\subsection{Cardiorespiratory Toxicity}

Anticancer treatment is usually accompanied by reduced cardiorespiratory function, which conversely leads to dose reduction or cessation of anticancer therapy. Cardiorespiratory toxicity in cancer results from chemotherapy-induced damage to cardiomyocytes, leading to cardiomyopathy, heart failure, acute myocardial infarction, arrhythmia, pulmonary fibrosis. The cardiorespiratory complication is one of the biggest causes of cancer-related mortality. These complications give rise to poor cardiac contractility and decreased ventricular ejection fraction, which causes insufficient oxygen transported by the circulatory system. The skeletal muscles need oxygen to generate adenosine triphosphate (ATP) to produce contraction; thus, poor oxygen-carrying capacity limits the individual physical capacity and ability to perform activities of daily living. This, therefore, dramatically reduces the QoL of cancer survivors [55]. Two major factors that contribute to reduced cardiovascular capacity induced by cancer treatment include (1) direct damage to cardiac muscle cells or lung tissue and (2) long-term cardiac disease caused by cancer treatment- 
induced metabolic syndrome. However, the exact mechanism of cardiotoxicity remains unknown. Evidence showed that miRNAs serve as key mediators in heart muscle cell proliferation, differentiation, and apoptosis. The most extensively investigated are the myomiR family, which refers to the miRNAs most expressed in the muscle tissue. Most myomiRs are expressed both in heart and skeletal muscle: miR-1, miR-133a, miR-133b, miR-486, and miR-499 [56], while some are only expressed in one muscle tissue: cardiospecific miR-208a and skeletal muscle-specific miR-206 [57]. Evidence illustrates that the dysregulation of myomiRs, along with metabolism-related miRNAs, was correlated to adverse cardiac remodelling and toxicity in both preclinical and clinical studies (for review, see Pellegrini et al. [22], Pereira et al. [58], and Riggeri et al. [59]). In neonatal cardiac rat models, the doxorubicin-induced upregulation of miR-146a facilitated cell death in myocytes by targeting ErbB4 and therefore caused cardiotoxicity [60]. The upregulation of miR-146a was also observed in doxorubicin-treated breast cancer patients [61]. Compared to non-anthracycline chemotherapy, the expression of miR-29a and miR-499 in plasma was elevated after anthracycline exposure. In addition, their higher expression in patients receiving anthracycline significantly correlated to dose and increased troponin levels [62].

Physical activity can improve cardiorespiratory function. Evidence showed that physiological response to exercise training results in the release of miRNAs in blood, which regulated the adaptive changes, such as muscle atrophy/hypertrophy, reflected by protein, glucose, and lipid metabolism, in the human body via IGF1/PI3K/AKT/mTOR signalling pathway. Therefore, great efforts are invested in exploring the effect of physical activity on miRNAs common to this particular pathway (for review, see Domańska-Senderowska et al. [40]). The expression of miRNA was significantly associated with changes in certain physiological parameters during exercise. The study showed that the expression of miR-1, $-133 \mathrm{a} / \mathrm{b}$, and miR-486 was correlated to $\mathrm{VO}_{2}$ max and anaerobic threshold [40], while circulating miR-486 was inversely correlated to resting heart rate [63]. These results indicated miRNAs might serve as biomarkers for cardiorespiratory function and fitness during physical activity.

\subsection{Cancer Cachexia}

Cancer cachexia is a complex multifactorial syndrome characterized by weight loss with the reduction of skeletal muscle and fat mass that affects $20 \%$ of cancer patients and is more prominent in refractory cancer patients [64]. The difference between malnutrition and cachexia is that cachexia is caused by loss of muscle mass and cannot be reversed by conventional nutritional interventions [65]. As a result, cachexia is deemed an independent predictor of cancer mortality. In animal models of cancer cachexia, the reversal of muscle loss gives rise to longer survival, making the biomarkers that regulate or mediate muscle atrophy to be of primary importance [66]. Recent work has shown that miRNAs were associated with the signalling pathway involved in the pathogenesis of cancer cachexia, especially the pathway of turnover of skeletal muscle and adipose tissue (for review, see Santos et al. [21]). Specifically, miRNAs modulate adipose and skeletal muscle tissue metabolism in cancer cachexia and also regulate tumour- and tissue-derived inflammation. Other studies have revealed that PI3K/Akt/mTOR and Akt/FoxO signalling pathways may play an important role in miRNA-mediated muscle atrophy. Narasimhan et al. [67] profiled the differentially expressed miRNAs in skeletal muscle between cachectic and non-cachectic cancer patients and identified eight upregulated miRNAs (upregulated, fold change of $\geq 1.4$ at $p<0.05$ ), namely hsa-miR-3184-3p, hsa-miR-423-5p, hsa-let-7d-3p, hsa-miR-1296-5p, hsa-miR-345-5p, hsa-miR-532-5p, hsa-miR-423-3p, and hsa-miR-199a-3p. In this work, Narasimhan et al. [67] also analysed the target gene and possible pathway to regulate cachexia including pathways involved in cytokine signalling and inflammation. Furthermore, these miRNAs showed significantly prognostic and predictive value in nonsmall cell lung cancer patients with cachexia, suggesting miRNAs may serve as potential biomarkers in cancer cachexia.

Physical activity is a potent nonpharmaceutical physiologic intervention to counteract cancer cachexia by improving and maintaining skeletal mass and strength. One of the 
possible mechanisms for this could be that physical activity brings about the changes of skeletal muscle-related miRNAs. MiRNAs play an intricate role in muscle biogenesis and development. Dysregulation of myomiRs, key mediators for muscle development, was associated with the dysfunction of the pathway that mediates myogenesis, muscle hypertrophy, and atrophy [68]. miRNAs were also associated with physiological measurements of cancer cachexia after exercise. Plasma miR-146a and miR-221 positively correlated with muscle mass and fat mass but negatively related to BMI [69]. Plasma miR-222 levels were positively associated with a strength-related performance measure; in contrast, plasma miR21, miR-221, and miR-146a levels were negatively related to a subset of strength-related performance measures [69].

\subsection{Depression and Anxiety}

Depression and anxiety are two of the most common psychological symptoms in cancer patients. Cancer diagnosis, cancer treatment, and all the accompanying side effects that lead to reduced QoL may cause and even aggravate depression and anxiety. As a result, depression and anxiety are more severe in cancer survivors than in the general population. Evidence showed that the prevalence of depression of cancer patients varied among different cancer types, ranging from 1.5 to 58\% [70]; anxiety ranged from 6 to $32.2 \%$ [71,72]. A study on depression in hospitalized cancer patients showed that $42 \%$ of oncologic inpatients met the criteria of major depression, with $24 \%$ with severe and $18 \%$ with moderately severe depression. In addition, $14 \%$ of cancer patients presented depressive symptoms though they did not meet the criteria of major depression [73]. Depression and anxiety have further negative effects on the QoL and correlated to elevated mortality in cancer survivors. Evidence supported that the mortality rate of cancer survivors who had depressive symptoms was $25 \%$, but this rate was elevated to $39 \%$ when cancer patients were diagnosed with depression [74]. Mean survival at 24 months for cancer patients without depression and anxiety was 23.11 months versus 20.87 months for those with [75]. So far, the depression or anxiety self-rate scale is the most commonly used tool in diagnosing and measuring depression or anxiety. Therefore, it is necessary to develop biomarkers as an early screening and intervention strategy for depression and anxiety in cancer patients. The aberrant expression of noncoding transcriptomic substances, such as miRNA, long noncoding RNA, and messenger RNA, lead to the impaired functions of hippocampus, which is associated with a variety of mental health issues, including depression and anxiety, and thus serve as biomarkers in depressive symptoms [40]. In particular, miRNAs had been proved to play an important role in both clinical depression and in animal models (for review, see Gururajan et al. [76], Malan-Müller et al. [77]). Evidence showed that the aberrant expression of miR-17-92 clusters in hippocampal progenitor significantly influenced neurogenesis and anxiety- and depression-related behaviours: miR-17-92 knockout induced anxiety and depression; miR-17-92 overexpression exhibited antianxiety- and antidepression-like behaviour. This may be involved in neurogenesis-related genes, serumand glucocorticoid-inducible protein kinase-1, in the glucocorticoid pathway [78]. Physical activity is an effective way to relieve depressive and anxious symptoms. In a study of effects of exercise dose and type on psychological distress in breast cancer patients, the recruited patients were assigned into three groups: a standard dose of aerobic exercise ( 25 to $30 \mathrm{~min}$ ), a higher dose of aerobic exercise (50 to $60 \mathrm{~min}$ ), and the combination of aerobic and resistance exercise (50 to $60 \mathrm{~min}$ ). All these exercise types can alleviate depressive symptoms in patients with clinical levels of depression at baseline. Still, this function cannot be observed among unselected breast cancer patients undergoing chemotherapy [79]. Another physical exercise rehabilitation program (10-week twice-weekly) also reported the apparent improvement of depression and anxiety in breast cancer patients [80]. Mounting evidence showed that aerobic exercise could improve the function of the hippocampus, the mechanism of which involved SIRT1/miRNAs pathway, thus mitigating depressive symptoms [40,81]. However, few studies investigated the relationship between physical activity-related miRNAs and cancer treatment-related depression and anxiety. Hence, fur- 
ther studies are required to investigate the changing pattern of miRNAs in cancer-related depression and anxiety during exercise-based cancer rehabilitation.

We summarized the miRNA expression in common cancer treatment-induced complications and physical activity in Figure 2, aiming to look for the potential biomarkers for exercise-based cancer rehabilitation.

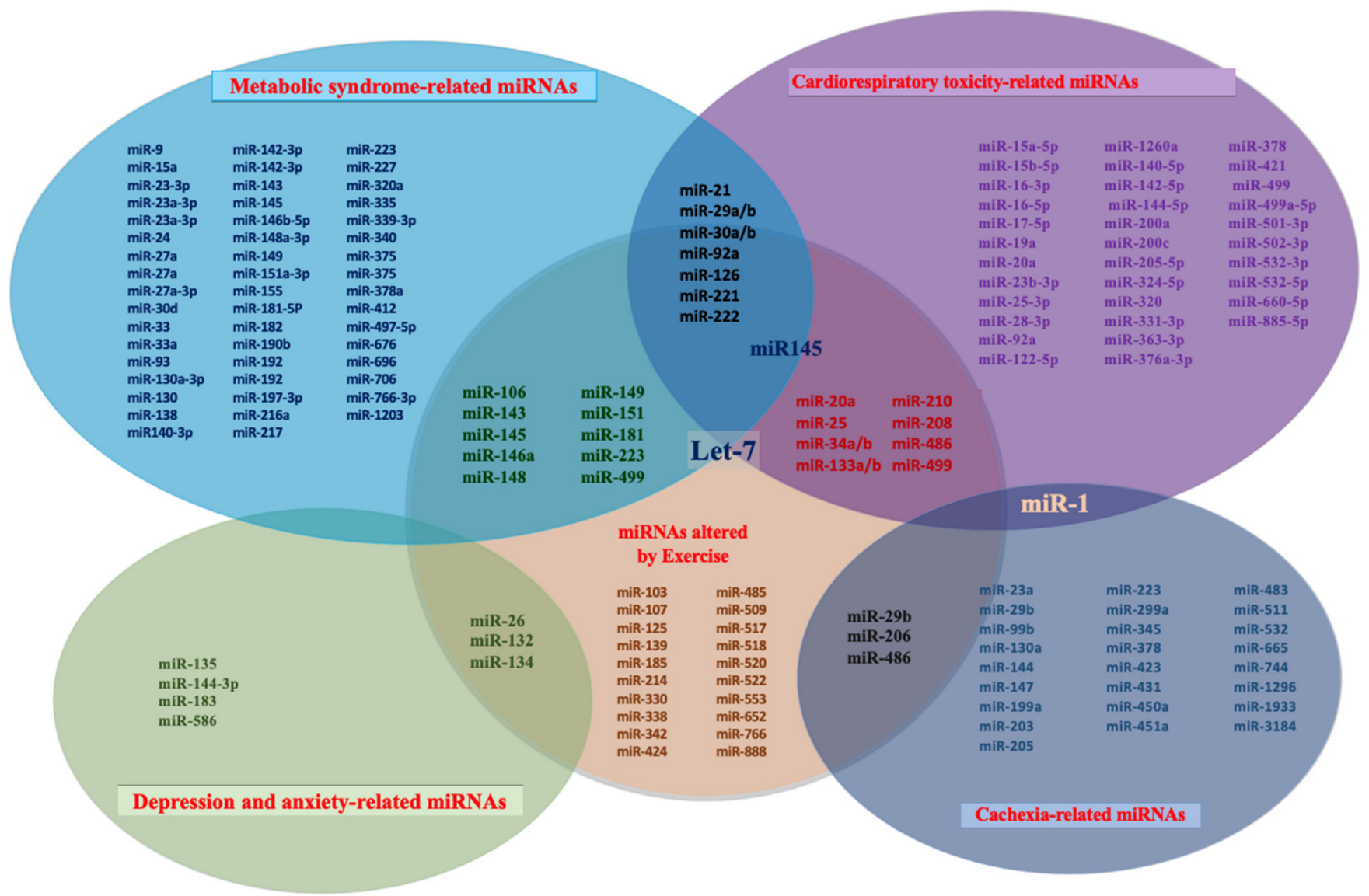

Figure 2. MiRNA expression in cancer treatment-induced complications and physical activity. The Venn diagram shows the differentially expressed miRNA in both common cancer treatment-induced complications (metabolic syndrome, cardiorespiratory toxicity, cachexia, depression, and anxiety) and physical activity (endurance training, aerobic training, or both) from literature. The overlapping miRNA may be potential biomarkers for exercise-based cancer rehabilitation for cancer survivors but remains to be investigated.

\section{Potential miRNAs as Biomarkers in Exercise-Based Cancer Rehabilitation}

\subsection{Metabolic Syndrome}

4.1.1. $\mathrm{miR}-126$ and $\mathrm{miR}-146 \mathrm{a}$

Gomes et al. [82] showed that obesity could lead to decreased expression of miR-126 and an increased PI3KR2, which inhibits a key regulator of the VEGF signalling pathway $P I 3 K$, thus causing capillary rarefaction in skeletal muscle in the obese rat model, whereas aerobic exercise training, such as swimming, can reverse this negative impact by normalizing miR-126 level and restoring VEGF signalling. Of note, other studies showed miR-126 increased in obese patients, but after physical activity, there was a slight decrease of miR-126, without statistical significance [83].

miRNA was associated with the metabolic disorder by regulating the inflammatory response in white adipose tissue, leading to insulin resistance. miR-146a can suppress the macrophage-conditioned medium-induced inflammatory response in adipocytes, which was reflected by a decrease of $I L-8, M C P-1$ mRNA and protein. The mechanism of this process involves a reduced inflammation-induced activation of $J N K$ and $p 38$ via targeting 
IRAK1 and TRAF6 in human adipocytes [84]. Studies [83] showed that miR-146a-5p significantly increased in obese patients. The increase of miR-146a-5p was also accompanied by an increase of inflammatory genes, such as TRL4, NF- $k B, I L-6$, and TNF- $\alpha$ in human mononuclear leukocytes, while, after exposure to physical activity, four-fifths of responders in these obese patients had a remarkable decrease of miR-146a-5p. In addition, miR-146a-5p was significantly correlated to lipid parameters, namely total cholesterol and inflammatory cytokine IL-8. These results indicated that miR-146a-5p might play a critical role in obesity by activating the inflammatory response and serve as a promising biomarker for obesity and its metabolic complications during exercise.

Gilberto et al. [85] analysed the relationship between circulating miRNAs and strength training in T2DM patients and found that diabetic patients exhibited an apparent reduction of blood sugar compared to nondiabetic patients after strength training. This reduction resulted in an increase of miR-146a in the blood instead of miR-126. Evidence suggested that miR-146a $\mathrm{a}^{-/-}$mice exposed to a high-fat diet gained more body weight and fat mass than controls, accompanied by insulin resistance and glucose intolerance. Both adipocytes transfected with miR146a and knockout of natriuretic peptide receptor 3 (NPR3), a target gene of miR-146a, exhibited an increase in insulin-stimulated glucose intake, demonstrating that miR-146a modulated insulin sensitivity by downregulating NPR3 [86]. These results indicated miR-146a might serve as a more promising biomarker to evaluate response to antidiabetic intervention than miR-126.

\subsection{2. $\mathrm{miR}-9$ and $\mathrm{miR}-375$}

Studies showed miR-375 and miR-9 presented a positive correlation to glycaemic status. Moreover, miR-375 showed good diagnostic abilities to distinguish prediabetes and T2DM patients from healthy controls, with area under curve (AUC) of 0.76 (95\% confidence interval (CI): $0.630-0.884, p=0.001)$ and 0.77 (95\% CI: $0.65-0.89, p<0.001)$ compared to miR-9 (prediabetes: $\mathrm{AUC}=0.63,95 \% \mathrm{CI}: 0.485-0.777, p=0.08$; T2DM: $\mathrm{AUC}=0.50$, 95\% CI: $0.301-0.604, p=0.053)$. Results also showed that the combination of miR-375 and miR-9 significantly enhanced the predictability to distinguish patients from controls. Taken together, miR-375 alone or combined with miR-9 could be used as biomarkers for prediabetes and T2DM [25]. Inhibiting insulin exocytosis by miR-9 and reducing the number and viability of pancreatic $\beta$-cells by overexpression of miR-375 may provide a theoretical basis for their application in T2DM diagnosis. Despite the diagnostic value or valid theoretical basis, few studies investigate the change of these two miRNAs in metabolic syndrome during exercise in cancer survivors.

\subsubsection{Others}

Other miRNAs, such as miR-92a, miR-130a, miR-222, and miR-370, were remarkably decreased in pre-atherosclerotic patients (patients without atherosclerosis but having hypertension, hyperlipidaemia, and/or diabetes), with miR-126 and miR-130a decreased up to 50\% [87]. Like miR-375 and miR-9, these miRNAs had been deeply investigated for the mechanism of the initiation of metabolic disease. Still, these studies did not establish a clinical correlation between metabolic syndrome and the miRNAs, and there was no overlap identified with physical activity or exercise training. Therefore, whether these miRNAs can be used for potential biomarkers of exercise-based cancer rehabilitation remains to be determined.

\subsection{Cardiorespiratory Capacity}

\subsection{1. myomiRs}

The elevation of circulating miR-1 was significantly associated with LVEF reduction, and the receiver operating characteristic curve (ROC) analysis showed that miR-1 exceeded cardiac troponin I (cTnI) in distinguishing potential victims to cardiotoxicity [61]. In rat models, 14 weeks of endurance training significantly increased the expression of miR-1 and miR-133, which can result in physiological hypertrophy by targeting downstream 
Srf, Hdac4, and Hand2 gene [88]. Moreover, circulating miR-1, miR-133a, and miR-206 were correlated to aerobic performance parameters such as $\mathrm{VO}_{2}$ max and running speed at individual anaerobic lactate thresholds in marathon runners [89]. Nielsen et al. [90] demonstrated that the expression of myomiRs in muscle biopsies, such as miR-1, miR-133a, miR-133b, and miR-206, were related to increased $\mathrm{VO}_{2}$ max and improved insulin sensitivity after endurance training. These results suggested that these myomiRs play a pivotal role in physical adaption during exercise. Nevertheless, Wardle et al. [69] found several myomiRs (miR-1, miR-133a, miR-206, miR-499) expressed at very low levels in the plasma. Although miRNAs at a low level are sufficient to cause physiological changes, whether or not the low level of miRNAs impacts, the correlation analysis remains unknown.

miR-208a, miR-208b, and miR-499 are all encoded by the myosin gene in muscle. Although miR-208a is cardiac-specific and its role in doxorubicin-induced cardiotoxicity has been validated in the mice model, its role in cancer patients seemed disappointing [61,91]. miR-208b and miR-499 were reported to rebound back to pre-exercise levels after $24 \mathrm{~h}$ of completion of the exercise in marathon runners. They were not correlated with cardiac injury markers, such as cTnI and B-type natriuretic peptide (NT-pro-BNP) [89]. These results suggested the limited role of these miRNAs to evaluate or monitor cardiovascular capacity in physical activity.

\subsection{2. $\mathrm{miR}-126$}

In rat models, miR-126, as a pre-angiogenic miRNA, played a critical role in having a cardioprotective effect after exposure to crocin and voluntary exercise, the mechanism of which involved facilitated cardiac angiogenesis through Akt and ERK1/2 pathways [83]. Furthermore, miR-126, which HIF-1 $\alpha$ induced during exercise training, also contributed to myocardial angiogenesis via the PI3K/AKT/eNOS and MAPK signalling pathway and subsequently improved heart function in myocardial infarction rats [92]. Exosomes from miR-126 overexpressing mesenchymal stem cells were shown to induce angiogenesis via the PIK3R2-mediated PI3K/Akt signalling pathway [84]. Moreover, miR-126 was positively correlated to NT-pro-BNP and CTN-I in atherosclerotic patients [87]. Exercise training reduced the high-density lipoprotein (HDL)-induced miR-126 in patients with chronic heart failure and eventually caused atherogenesis and endothelial dysfunction [93]. These results suggested miR-126 was associated with common indicators of cardiac damage and may serve as a potential biomarker for treatment-induced cardiotoxicity as well we exercise-based cardiac and cancer rehabilitation.

\subsection{3. $\mathrm{miR}-21$ and $\mathrm{miR}-146 \mathrm{a}$}

miR-21 and miR-146a are highly responsive to both cardiac damage and physical activity. miR-21 can attenuate diastolic dysfunction of diabetic cardiomyopathy via targeting gelsolin [94]. Like miR-126, miR-21, as a mediator, can promote hypoxia-induced angiogenesis in the cardiac microvascular endothelial cells [95]. Other studies have shown the relationship between miRNAs and common indicators of cardiac damage. miR-21 was negatively correlated to NT-pro-BNP and cTN-I among atherosclerotic patients [87]. In myocardial infarction in rat models, the injection of miR-146 antagomiR improved the reduction of left ventricular ejection fraction LVEF and fractional shortening. miR-146 antagomiR also reduced the levels of atrial natriuretic peptide (ANP) and BNP mRNA. In addition, miR-146 myomiRs attenuated cardiac fibrosis by reducing the increase of collagen I and collagen III mRNA. These results demonstrated that inhibition of miR-146 ameliorated cardiac dysfunction and remodelling [96]. A linear correlation between circulating miR-146a and cardiac marker creatine kinase-MB (CKMB) isoenzyme as well as high sensitivity C-reactive protein (hs-CRP) was observed in basketball players [97]. Studies showed that miR-21 and miR-146a had an opposite expression pattern and function during exercise: miR-21 had proinflammatory effects and was upregulated after acute exercise but downregulated after endurance training. By contrast, miR-146a had a proinflammatory effect and was upregulated by acute cycling exercise before and after 90 days of sustained rowing 
training. Additionally, the expression of miR-21 was negatively correlated with $\mathrm{VO}_{2}$ max, while miR-146a was positively correlated with $\mathrm{VO}_{2} \max [98,99]$, suggesting promising prospects in an exercise-based rehabilitation program.

\subsection{4. $\mathrm{miR}-222$}

In a study with HER-2 positive breast cancer patients undergoing neoadjuvant target therapy Trastuzumab, serum miR-222-3p protected against the relative drop of LVEF $(\mathrm{OR}=0.410,95 \%$ CI: $0.175-0.962, p=0.040)$ and absolute drop of LVEF (OR $=0.394,95 \%$ CI: $0.166-0.937, p=0.035)$, demonstrating that miR-222-3p was an independent protective factor for trastuzumab-induced cardiotoxicity [100]. Recent work suggested that highintensity interval training increased miR-222 expression after an acute bout of exercise and following a sustained period of exercise [101]. Liu et al. [102] suggested that miR-222 is necessary for exercise-induced cardiac growth and to counteract pathological cardiac remodelling via targeting $P 27, H I P K 1$, and $H M B O X 1$. This may explain how exercise benefits cardiovascular fitness. Despite the positive effects of miR-222 on cardiac physiology, miR-222 can inhibit $p 27^{K i p 1}$, a cyclin-dependent kinase inhibitor, thus promoting cancer growth [103]. Moreover, a low level of serum miR-222 was associated with superior pathological complete response, disease-free survival, and overall survival in breast cancer patients who received Trastuzumab [100]. These results suggested that miR-222 was a promising biomarker for cardiac fitness but a double-edged sword in the QoL of cancer survivors.

\subsection{5. $\mathrm{miR}-155$}

In fibrotic illnesses, miR-155 is persistently elevated, and knocking it out reduces collagen synthesis [104]. In vivo studies showed that miR-155-5p was significantly downregulated in radiation-induced EMT cell model, while in vitro studies showed that ectopic overexpression of miRNA-155-5p inhibited EMT through the NF-KB pathway by targeting GSK-3 $\beta$. This alleviated radiation-induced pulmonary fibrosis [105]. In the mouse model of bleomycin-induced pulmonary fibrosis, the miRNA-155/LXR pathway was identified to play an important role in experimental and idiopathic pulmonary fibrosis [106]. In another study, untrained rats showed enhanced acetylcholine (Ach)-induced relaxation and nitric oxide (NO) production compared to trained rats. Results showed a higher expression of endothelial NO synthase (eNOS), the posttranslational modification of which by the PI3-kinase/Akt1/2/3 pathway, contributed to higher production of exercise-induced NO expression, which was associated with a lower level of miR-155, indicating that the favourable effects of exercise on the circulating system may involve the participation of miR-155 in the molecular mechanism of improved vascular relaxation in muscular arteries [107]. Despite an increase of miR-155 in blood and no relationship between miR-155 and $\mathrm{VO}_{2}$ max in healthy people after exercise training, the relationship between miR-155 and respiratory fitness in treatment-induced pulmonary patients remains to be determined $[89,108]$.

\subsubsection{Others}

A systematic review for breast cancer patients suggested that let-7, miR-20a, and miR-210 may serve as biomarkers for anthracycline-based cardiotoxicity during chemotherapy [58]. In the rat model treated with doxorubicin at increasing doses, the level of cTnT was significantly elevated in the $18 \mathrm{mg} / \mathrm{kg}$ dose. The decrease of let-7g levels accompanied it. Only a few studies investigated the change of let- 7 in cardiotoxic patients after physical activity [109]. By targeting PTEN, miR-20a prevented exercise-associated CVD, but whether miR-20a played a role in reversing treatment-induced CVD remains unknown [110]. Accumulating evidence suggested that the expression of miR-210 was inversely associated with $\mathrm{VO}_{2}$ max after physical activity. A possible explanation is that, during exercise, a hypoxic condition in cardiac muscle triggered angiogenesis through HIF- $1 \alpha$-induced miR-210 [83]. Further efforts are required to establish a correlation between these miRNAs and physical and physiologic parameters in cancer survivors. 


\subsection{Cancer Cachexia}

\subsection{1. $\mathrm{miR}-21$}

Evidence suggested that miR-21 was upregulated in denervated muscles. miR21, along with miR-206, was sufficient for the atrophy process by targeting $Y Y 1$ and eIF4E3 [111]. He et al. [112] showed that tumour-derived microvesicles containing miR-21 could induce apoptosis of muscle cells through Toll-like 7 receptors on murine myoblasts. Moreover, c-Jun N-terminal kinase activity is required to mediate this apoptotic response. This may shed light on how tumour cells promote loss of muscle mass. Taken together, miR21 plays an important role in myogenesis and muscle mass gain. Other studies showed that low psoas muscle mass index was a prognostic biomarker for metastasis in colorectal cancer patients. The level of serum miR-21 was significantly elevated in colorectal cancer patients with low psoas muscle mass. This indicated that serum miR-21 quantification might help clinicians make decisions on developing intervention strategies for these patients [113]. However, it should be noted that miR-21 also regulated muscle loss in a natural process, such as ageing [114]. Additionally, evidence showed that levels of serum miR-21 and other miRNAs, such as miR-146a, miR-221, and miR-222, are unrelated to muscle bulk and fat reserve in athletes [97]. Few studies were conducted to explore the relationship between miR-21 and muscle mass and strength gain induced by physical activity, which therefore require further investigation.

\subsection{2. $\mathrm{miR}-378$}

In vivo study showed that training-induced change of miR-378 was positively associated with muscle mass gains. However, miR-378 was downregulated in low responders to resistance exercise amongst weightlifters. In contrast, an increase in miR-378 was not observed in high responders [39]. Aside from the loss of muscle mass, cancer cachexia is also associated with a significant loss of adipose tissue, which is caused by enhanced lipolysis in adipocytes in some but not all patients. Kulyte et al. [64] detected the expression of miR-378 in abdominal subcutaneous adipose tissue from gastrointestinal cancer patients and found that miR-378 was significantly elevated in cachectic cancer patients compared to non-cachectic patients. Overexpression of miR-378 was positively associated with loss of adipose tissue, which involved catecholamine-stimulated lipolysis in adipocytes. Inversely, inhibition of miR-378 can reduce the expression of LIPE, PLIN1, and PNPLA2 genes, which encoded key regulators for lipolysis and therefore decreased catecholamine-stimulated lipolysis. In vivo study showed that exercise-induced change in miR-378 abundance was positively correlated to muscle mass gain [39].

\subsection{3. $\mathrm{miR}-1$ and $\mathrm{miR}-133$}

Although miR-1 and miR-133 are clustered on the same chromosomal loci, they have very distinct roles in transcriptional circuits and therefore differentially regulate skeletal muscle cell proliferation and differentiation. miR-1 promotes myogenesis by targeting transcriptional gene histone deacetylase 4 in muscle, while miR-133 enhances myoblast proliferation by inhibiting serum response factor [115]. Moreover, miR-1 and miR-133 show different expression patterns in response to aerobic and resistance exercises. Both miRNAs were upregulated within three hours following an acute aerobic exercise bout but downregulated after four weeks of aerobic endurance training [116]. Again they decreased after $6 \mathrm{~h}$ of resistance training and remained downregulated after a week of resistance exercise training [116]. Recent work suggested that reduced IGF-1 protein was associated with upregulated miR-133 during the differentiation of $\mathrm{C} 2 \mathrm{C} 12$ cells. Overexpression of miR133 during differentiation significantly suppressed the expression of the IGF-1 receptor at the transcriptional level by downregulating the phosphorylation of Akt. Moreover, the upregulation of miR-133 can be accelerated by the addition of IGF-1. These results indicated that metabolism-related factors played an important role in myogenesis $[116,117]$. MiR-133a-deficient mice had a low maximal exercise capacity and low resting metabolic rate. The downregulated transcription of a set of mitochondrial biogenesis regulators, 
such as nuclear respiratory factor-1, transcription factor A, and so on, may explain lower mitochondrial mass and impaired exercise capacity in miR-133a-deficient mice. Six weeks of endurance training improved the expression of miR-133a and stimulated mitochondrial biogenesis in wild-type mice but failed to enhance the mitochondrial function in miR-133adeficient mice [118]. Mechanistic analysis showed IGF-1 receptor, the target of miR-133a, and the hyperactivation of $A k t$ signalling were involved in the lower transcription of the mitochondrial biogenesis regulators [118]. These results suggested that miR-133a reduced exercise capacity by lowering mitochondrial function. However, few studies were conducted to establish the correlation between the expression of miR-1 and miR-133 and muscle mass or strength after exercise training.

\subsection{Depression and Anxiety}

\subsection{1. let-7}

Evidence showed that depressed patients with 3-month treatment with antidepressants reported an elevation of a series of let-7 family members in blood, suggesting let-7 may be a therapeutic target in depression [119]. In a genetic rat model of depression, the decreased let-7 could increase the levels of the proinflammatory cytokine IL-6, leading to depression. On the other hand, running can reduce the level of $I L-6$ and rescue the expression of let-7i. This can elevate mood, thus exerting an antidepressant-like effect [120]. Studies showed that the baseline level of let- $7 \mathrm{~b}$ in treatment-resistant depression patients was $40 \%$ lower than healthy controls. In comparison, let-7c was 50\% lower in treatment-resistant depression patients who received electroconvulsive therapy when compared to healthy controls. Their role in depression may involve in PI3k-Akt-mTOR signalling pathway [121]. Hung et al. [122] demonstrated that the level of let-7e before starting antidepressant treatment was inversely correlated to the severity of depression. The expression of let-7e was also altered by antidepressant treatment, but whether let-7e levels were affected by exercise training remains unknown.

\subsection{2. $\mathrm{miR}-132$ and $\mathrm{miR}-182$}

In vitro study showed that miR-132 and miR-182 reduced the expression of brainderived neurotrophic factor (BDNF), which was greatly important in the aetiology of depression. Patients with depressive symptoms had lower BDNF levels and higher miR132 and miR-182 levels in blood compared to healthy controls. This supports the role of miR-132 and miR-182 in regulating BDNF expression [123]. Additionally, the self-rating depression scale (SDS) score was negatively correlated to serum BDNF levels but positively correlated to serum miR-132 levels. In contrast, the serum BDNF expression was reversely associated with the expression of miR-132/miR-182 [123]. In a rat model, downregulation of miR-132 can mitigate behavioural impairment of rats exposed to single prolonged stress, the mechanism of which may involve methyl GpG-binding protein 2, a positive mediator of BDNF regulated by miR-132-3p [124]. These results indicated that miR-132 and miR-182 may play a critical role in the BDNF-mediated pathway and may serve as diagnostic or therapeutic targets of mental disorders. Although a change of miR-132 was observed after endurance training, which can also reduce depressive symptoms in humans, whether the positive effect of exercise on depression involved the miR-132 regulatory pathway remains to be determined.

\subsection{3. $\mathrm{miR}-134$}

An enriched environment could ameliorate depressive-like behaviours caused by chronic unpredictable mild distress (CUMS). The SIRT1/miR-134 signalling pathway regulates its downstream molecules, including synaptic plasticity proteins and BDNF expression in primary cultured hippocampal neurons. The protective effect of an enriched environment may be through activating the SIRT1/miR-134 signalling pathway, remodelling the dendritic spine, altering synaptic ultrastructure, and increasing synaptic plasticity proteins and BDNF expression in the hippocampus [14]. 


\subsection{4. $\mathrm{miR}-34 \mathrm{~b} / \mathrm{c}$}

After exposure to NBI-27914, a specific corticotropin-releasing hormone receptor 1 (CRHR1) antagonist, which was correlated to trauma-induced anxiety, the rat model was observed for changes in the hypothalamic-pituitary adrenal (HPA) axis and anxietylike behaviour. Bioinformatic analysis showed that CRHR1 was the target of miR-34b, and the overexpression of miR-34b negatively modulated CRHR1 mRNA in the primary hypothalamic neurons, mitigating the hyperactivity of the HPA axis and anxiety-like behaviour [125]. Evidence also showed that $\mathrm{miR}-34 \mathrm{~b} / \mathrm{c}$ had a negative impact on the cognitive function of major depressive patients [126]. However, few studies explored how physical exercise alleviates psychological symptoms by modulating the expression of $\mathrm{miR}-34 \mathrm{~b} / \mathrm{c}$.

\subsubsection{Others}

In addition to miR-132 and miR-134, CUMS gives rise to depression-like behaviours via SIRT1/miR-124, and swimming exercise can reverse the expression of SIRT1 protein and the expression of these miRNAs in CUMS mice. However, the correlation between depressive behaviour and epigenetic changes of hippocampal plasticity was not established [81]. In major depressive disorder patients, intracellular miR-146a level was negatively correlated with the severity of depression; by contrast, miR-155 showed the opposite effect [122]. However, their role in exercise-related prevention of depression requires further investigation.

\section{The Challenge of miRNAs as Biomarkers in Exercise-based Cancer Rehabilitation}

Albeit the promising prospect of miRNAs as potential biomarkers for exercise-based cancer rehabilitation, there are several issues remaining to be resolved: (1) clinical correlation between miRNAs expression in specific tissues and their expression in blood as well as physiological and physical parameters in cancer rehabilitation should be established due to the lack of related investigation; (2) the changing pattern of miRNAs differs from conventional biomarkers after exercise: NT-proBNP and hs-CRP increased after the marathon and stay elevated after $24 \mathrm{~h}$ of race completion. By contrast, circulating miRNAs elevated instantly after the race and returned to prerace level or even lower $24 \mathrm{~h}$ postrace. These results suggested that circulating release and clearance mechanisms of miRNAs may differ from traditional biomarkers and that miRNAs may serve as real-time and simultaneous instead of long-term markers of exercise-induced muscle adaptation [127]. In addition, most studies investigated the effect of physical activity on miRNAs among healthy people or athletes, and few studies focus on the change of miRNAs on the deconditioned cancer patients during exercise. Therefore, it is necessary to conduct research exploring the effect of exercise-based rehabilitation on the dynamic change of miRNAs in cancer survivors; (3) miRNAs were associated with age, gender, training modality, or exercise regimen; we should, therefore, adjust these factors before we put miRNAs in use; (4) miRNAs at very low-level change are sufficient to cause an imbalance of human body by binding to multiple target genes [69]. Thus, the target gene in a regulatory network needs to be fully elucidated. Thus, the target gene, as an auxiliary tool for miRNAs in rehabilitation, opens a new opportunity for future investigation.

Author Contributions: Conceptualization and Supervision: A.G.; Writing: Y.J.; Editing: K.G.; Review: S.G. All authors have read and agreed to the published version of the manuscript.

Funding: This work was supported by China Scholarship Council PhD scholarship supporting Y.Jiang and Athena Swan Research Capacity Building fund 2021 National University of Ireland, Galway, received by Gupta.

Institutional Review Board Statement: Not applicable.

Informed Consent Statement: Not applicable. 


\section{Data Availability Statement: Not applicable.}

Conflicts of Interest: The authors declare that the research was conducted in the absence of any commercial or financial relationships that could be construed as a potential conflict of interest.

\section{References}

1. Ferlay, J.; Colombet, M.; Soerjomataram, I.; Mathers, C.; Parkin, D.M.; Piñeros, M.; Znaor, A.; Bray, F. Estimating the global cancer incidence and mortality in 2018: GLOBOCAN sources and methods. Int. J. Cancer 2019, 144, 1941-1953. [CrossRef] [PubMed]

2. Torre, L.A.; Bray, F.; Siegel, R.L.; Ferlay, J.; Lortet-Tieulent, J.; Jemal, A. Global cancer statistics, 2012. CA Cancer J. Clin. 2015, 65, 87-108. [CrossRef] [PubMed]

3. Ivers, M.E.; Dooley, B.A.; Bates, U. Development, Implementation and Evaluation of a Multidisciplinary Cancer Rehabilitation Programme: The CANSURVIVOR Project: Meeting Post-Treatment Cancer Survivors' Needs; Health Services Executive: Cancer Care Services HSE Dublin Mid-Leinster: Dublin, Ireland, 2009.

4. Mullen, L.; Hanan, T. National Cancer Survivorship Needs Assessment: Living with and beyond Cancer in Ireland; National Cancer Control Programme: Dublin, Ireland, 2019.

5. Donnelly, C.; O'Connor, M.; O' Donovan, B.; Drummond, F. The Unmet Needs of Cancer Survivors in Ireland: A Scoping Review; National Cancer Registry Ireland: Cork, Ireland, 2019.

6. Mishra, S.I.; Scherer, R.W.; Snyder, C.; Geigle, P.; Gotay, C. Are Exercise Programs Effective for Improving Health-Related Quality of Life Among Cancer Survivors? A Systematic Review and Meta-Analysis. Oncol. Nurs. Forum 2014, 41, E326-E342. [CrossRef]

7. Gegechkori, N.; Haines, L.; Lin, J.J. Long-Term and Latent Side Effects of Specific Cancer Types. Med Clin. N. Am. 2017, 101, 1053-1073. [CrossRef] [PubMed]

8. Scott, D.A.; Mills, M.; Black, A.; Cantwell, M.; Campbell, A.; Cardwell, C.; Porter, S.; Donnelly, M. Multidimensional rehabilitation programmes for adult cancer survivors. Cochrane Database Syst. Rev. 2013, 2013, CD007730. [CrossRef] [PubMed]

9. Stene, G.; Helbostad, J.; Balstad, T.R.; Riphagen, I.; Kaasa, S.; Oldervoll, L. Effect of physical exercise on muscle mass and strength in cancer patients during treatment-A systematic review. Crit. Rev. Oncol. 2013, 88, 573-593. [CrossRef] [PubMed]

10. Dieli-Conwright, C.M.; Courneya, K.S.; Demark-Wahnefried, W.; Sami, N.; Lee, K.; Buchanan, T.A.; Spicer, D.V.; Tripathy, D.; Bernstein, L.; Mortimer, J. Effects of Aerobic and Resistance Exercise on Metabolic Syndrome, Sarcopenic Obesity, and Circulating Biomarkers in Overweight or Obese Survivors of Breast Cancer: A Randomized Controlled Trial. J. Clin. Oncol. 2018, 36, 875-883. [CrossRef]

11. Messaggi-Sartor, M.; Marco, E.; Martínez-Téllez, E.; Rodriguez-Fuster, A.; Palomares, C.; Chiarella, S.; Muniesa, J.M.; OrozcoLevi, M.; Barreiro, E.; Güell, M.R. Combined aerobic exercise and high-intensity respiratory muscle training in patients surgically treated for non-small cell lung cancer: A pilot randomized clinical trial. Eur. J. Phys. Rehabil. Med. 2019, 55, 113-122. [CrossRef] [PubMed]

12. Adams, S.; Segal, R.J.; McKenzie, D.C.; Vallerand, J.R.; Morielli, A.R.; Mackey, J.R.; Gelmon, K.; Friedenreich, C.; Reid, R.D.; Courneya, K.S. Impact of resistance and aerobic exercise on sarcopenia and dynapenia in breast cancer patients receiving adjuvant chemotherapy: A multicenter randomized controlled trial. Breast Cancer Res. Treat. 2016, 158, 497-507. [CrossRef]

13. Courneya, K.S.; Segal, R.J.; Mackey, J.R.; Gelmon, K.; Reid, R.D.; Friedenreich, C.M.; Ladha, A.B.; Proulx, C.; Vallance, J.K.; Lane, K.; et al. Effects of Aerobic and Resistance Exercise in Breast Cancer Patients Receiving Adjuvant Chemotherapy: A Multicenter Randomized Controlled Trial. J. Clin. Oncol. Off. J. Am. Soc. Clin. Oncol. 2007, 25, 4396-4404. [CrossRef]

14. Shen, J.; Li, Y.; Qu, C.; Xu, L.; Sun, H.; Zhang, J. The enriched environment ameliorates chronic unpredictable mild stress-induced depressive-like behaviors and cognitive impairment by activating the SIRT1/miR-134 signaling pathway in hippocampus. J. Affect. Disord. 2019, 248, 81-90. [CrossRef] [PubMed]

15. Dieli-Conwright, C.M.; Courneya, K.S.; Demark-Wahnefried, W.; Sami, N.; Lee, K.; Sweeney, F.C.; Stewart, C.; Buchanan, T.A.; Spicer, D.; Tripathy, D.; et al. Aerobic and resistance exercise improves physical fitness, bone health, and quality of life in overweight and obese breast cancer survivors: A randomized controlled trial. Breast Cancer Res. 2018, 20, 124. [CrossRef] [PubMed]

16. Dong, X.; Yi, X.; Gao, D.; Gao, Z.; Huang, S.; Chao, M.; Chen, W.; Ding, M. The effects of the combined exercise intervention based on internet and social media software (CEIBISMS) on quality of life, muscle strength and cardiorespiratory capacity in Chinese postoperative breast cancer patients: A randomized controlled trial. Health Qual. Life Outcomes 2019, 17, 1-9. [CrossRef]

17. Jacot, W.; Arnaud, A.; Jarlier, M.; Lefeuvre-Plesse, C.; Dalivoust, P.; Senesse, P.; Azzedine, A.; Tredan, O.; Sadot-Lebouvier, S.; Mas, S.; et al. Brief Hospital Supervision of Exercise and Diet During Adjuvant Breast Cancer Therapy Is Not Enough to Relieve Fatigue: A Multicenter Randomized Controlled Trial. Nutrients 2020, 12, 3081. [CrossRef] [PubMed]

18. Vincent, F.; Labourey, J.L.; Leobon, S.; Antonini, M.T.; Lavau-Denes, S.; Mathieu, N.T. Effects of a home-based walking training program on cardiorespiratory fitness in breast cancer patients receiving adjuvant chemotherapy: A pilot study. Eur. J. Phys. Rehabil. Med. 2013, 49, 319-329.

19. Van Waart, H.; Stuiver, M.M.; van Harten, W.H.; Sonke, G.S.; Aaronson, N.K. Design of the Physical exercise during Adjuvant Chemotherapy Effectiveness Study (PACES): A randomized controlled trial to evaluate effectiveness and cost-effectiveness of physical exercise in improving physical fitness and reducing fatigue. BMC Cancer 2010, 10, 673. [CrossRef] 
20. Vincent, F.; Deluche, E.; Bonis, J.; Leobon, S.; Antonini, M.-T.; Laval, C.; Favard, F.; Dobbels, E.; Lavau-Denes, S.; Labrunie, A.; et al. Home-Based Physical Activity in Patients with Breast Cancer: During and/or After Chemotherapy? Impact on Cardiorespiratory Fitness. A 3-Arm Randomized Controlled Trial (APAC). Integr. Cancer Ther. 2020, 19, 153473542096981. [CrossRef] [PubMed]

21. Santos, J.M.O.; Da Silva, S.P.; Da Costa, R.M.G.; Medeiros, R. The Emerging Role of MicroRNAs and Other Non-Coding RNAs in Cancer Cachexia. Cancers 2020, 12, 1004. [CrossRef] [PubMed]

22. Pellegrini, L.; Sileno, S.; D'Agostino, M.; Foglio, E.; Florio, M.C.; Guzzanti, V.; Russo, M.A.; Limana, F.; Magenta, A. MicroRNAs in Cancer Treatment-Induced Cardiotoxicity. Cancers 2020, 12, 704. [CrossRef]

23. Manna, I.; De Benedittis, S.; Quattrone, A.; Maisano, D.; Iaccino, E.; Quattrone, A. Exosomal miRNAs as Potential Diagnostic Biomarkers in Alzheimer's Disease. Pharmaceuticals 2020, 13, 243. [CrossRef]

24. Kulkarni, B.; Kirave, P.; Gondaliya, P.; Jash, K.; Jain, A.; Tekade, R.K.; Kalia, K. Exosomal miRNA in chemoresistance, immune evasion, metastasis and progression of cancer. Drug Discov. Today 2019, 24, 2058-2067. [CrossRef] [PubMed]

25. Al-Muhtaresh, H.A.; Al-Kafaji, G. Evaluation of Two-Diabetes Related microRNAs Suitability as Earlier Blood Biomarkers for Detecting Prediabetes and type 2 Diabetes Mellitus. J. Clin. Med. 2018, 7, 12. [CrossRef] [PubMed]

26. Mehta, M.; Satija, S.; Paudel, K.R.; Malyla, V.; Kannaujiya, V.K.; Chellappan, D.K.; Bebawy, M.; Hansbro, P.M.; Wich, P.R.; Dua, K. Targeting respiratory diseases using miRNA inhibitor based nanotherapeutics: Current status and future perspectives. Nanomed. Nanotechnol. Biol. Med. 2021, 31, 102303. [CrossRef] [PubMed]

27. Wang, J.; Jiang, Q.; Faleti, O.D.; Tsang, C.-M.; Zhao, M.; Wu, G.; Tsao, S.-W.; Fu, M.; Chen, Y.; Ding, T.; et al. Exosomal Delivery of AntagomiRs Targeting Viral and Cellular MicroRNAs Synergistically Inhibits Cancer Angiogenesis. Mol. Ther. Nucleic Acids 2020, 22, 153-165. [CrossRef] [PubMed]

28. Kardani, A.; Yaghoobi, H.; Alibakhshi, A.; Khatami, M. Inhibition of miR-155 in MCF-7 breast cancer cell line by gold nanoparticles functionalized with antagomir and AS1411 aptamer. J. Cell. Physiol. 2020, 235, 6887-6895. [CrossRef] [PubMed]

29. Song, M.-S.; Rossi, J.J. The anti-miR21 antagomir, a therapeutic tool for colorectal cancer, has a potential synergistic effect by perturbing an angiogenesis-associated miR30. Front. Genet. 2014, 4, 301. [CrossRef]

30. Ma, L.; Reinhardt, F.; Pan, E.; Soutschek, J.; Bhat, B.; Marcusson, E.G.; Teruya-Feldstein, J.; Bell, G.W.; A Weinberg, R. Therapeutic silencing of miR-10b inhibits metastasis in a mouse mammary tumor model. Nat. Biotechnol. 2010, 28, 341-347. [CrossRef]

31. Heneghan, H.; Miller, N.; Kelly, R.; Newell, J.; Kerin, M. Systemic miRNA-195 Differentiates Breast Cancer from Other Malignancies and Is a Potential Biomarker for Detecting Noninvasive and Early Stage Disease. Oncologist 2010, 15, 673-682. [CrossRef]

32. Ng, E.K.O.; Li, R.; Shin, V.Y.; Jin, H.C.; Leung, C.P.H.; Ma, E.S.K.; Pang, R.; Chua, D.; Chu, K.-M.; Law, W.L.; et al. Circulating microRNAs as Specific Biomarkers for Breast Cancer Detection. PLoS ONE 2013, 8, e53141. [CrossRef]

33. Torres, A.; Torres, K.; Pesci, A.; Ceccaroni, M.; Paszkowski, T.; Cassandrini, P.; Zamboni, G.; Maciejewski, R. Diagnostic and prognostic significance of miRNA signatures in tissues and plasma of endometrioid endometrial carcinoma patients. Int. J. Cancer 2013, 132, 1633-1645. [CrossRef]

34. Shin, V.Y.; Ng, E.K.O.; Chan, V.W.; Kwong, A.; Chu, K.-M. A three-miRNA signature as promising non-invasive diagnostic marker for gastric cancer. Mol. Cancer 2015, 14, 202. [CrossRef] [PubMed]

35. Ha, T.-Y. MicroRNAs in Human Diseases: From Cancer to Cardiovascular Disease. Immune Netw. 2011, 11, 135. [CrossRef] [PubMed]

36. Van Schooneveld, E.; Wouters, M.C.; Van Der Auwera, I.; Peeters, D.J.; Wildiers, H.; A Van Dam, P.; Vergote, I.; Vermeulen, P.B.; Dirix, L.Y.; Van Laere, S.J. Expression profiling of cancerous and normal breast tissues identifies microRNAs that are differentially expressed in serum from patients with (metastatic) breast cancer and healthy volunteers. Breast Cancer Res. 2012, 14, R34. [CrossRef] [PubMed]

37. Treiber, T.; Treiber, N.; Meister, G. Regulation of microRNA biogenesis and its crosstalk with other cellular pathways. Nat. Rev. Mol. Cell Biol. 2019, 20, 5-20. [CrossRef] [PubMed]

38. Kangas, R.; Pöllänen, E. Physical activity responsive miRNAs-Potential mediators of training responses in human skeletal muscle? J. Sport Health Sci. 2013, 2, 101-103. [CrossRef]

39. Davidsen, P.K.; Gallagher, I.; Hartman, J.W.; Tarnopolsky, M.A.; Dela, F.; Helge, J.; Timmons, J.A.; Phillips, S. High responders to resistance exercise training demonstrate differential regulation of skeletal muscle microRNA expression. J. Appl. Physiol. 2011, 110, 309-317. [CrossRef]

40. Domańska-Senderowska, D.; Laguette, M.-J.N.; Jegier, A.; Cieszczyk, P.; September, A.V.; Brzeziańska-Lasota, E. MicroRNA Profile and Adaptive Response to Exercise Training: A Review. Int. J. Sports Med. 2019, 40, 227-235. [CrossRef]

41. Polakovičová, M.; Musil, P.; Laczo, E.; Hamar, D.; Kyselovič, J. Circulating MicroRNAs as Potential Biomarkers of Exercise Response. Int. J. Mol. Sci. 2016, 17, 1553. [CrossRef]

42. Yamada, R.; Okumura, S.; Kono, Y.; Miyazaki, A.; Niwa, Y.; Ito, T.; Ueda, S.; Ishiguro, T.; Yoshinaga, M.; Fujiwara, W.; et al. Effect of cardiac rehabilitation on circulating microRNA expression in heart failure: A preliminary study. Fujita Med. J. 2020, 7, 76-82. [CrossRef]

43. La Rosa, F.; Agostini, S.; Saresella, M.; Costa, A.S.; Piancone, F.; Miglioli, R.; Trecate, F.; Clerici, M. Deregulation of IL-37 and its miRNAs modulators in sarcopenic patients after rehabilitation. J. Transl. Med. 2021, 19, 172. [CrossRef]

44. Eckel, R.H.; Grundy, S.M.; Zimmet, P.Z. The metabolic syndrome. Lancet 2005, 365, 1415-1428. [CrossRef] 
45. Esposito, K.; Chiodini, P.; Colao, A.; Lenzi, A.; Giugliano, D. Metabolic Syndrome and Risk of Cancer: A systematic review and meta-analysis. Diabetes Care 2012, 35, 2402-2411. [CrossRef] [PubMed]

46. Westerink, N.; Nuver, J.; Lefrandt, J.; Vrieling, A.; Gietema, J.; Walenkamp, A. Cancer treatment induced metabolic syndrome: Improving outcome with lifestyle. Crit. Rev. Oncol. Hematol. 2016, 108, 128-136. [CrossRef] [PubMed]

47. Braun, S.; Bitton-Worms, K.; Leroith, D. The Link between the Metabolic Syndrome and Cancer. Int. J. Biol. Sci. 2011, 7, 1003-1015. [CrossRef]

48. Blijdorp, K.; van Waas, M.; van der Lely, A.-J.; Pieters, R.; van den Heuvel-Eibrink, M.; Neggers, S. Endocrine sequelae and metabolic syndrome in adult long-term survivors of childhood acute myeloid leukemia. Leuk. Res. 2013, 37, 367-371. [CrossRef]

49. Braga-Basaria, M.; Dobs, A.S.; Muller, D.C.; Carducci, M.A.; John, M.; Egan, J.; Basaria, S. Metabolic Syndrome in Men with Prostate Cancer Undergoing Long-Term Androgen-Deprivation Therapy. J. Clin. Oncol. Off. J. Am. Soc. Clin. Oncol. 2006, 24, 3979-3983. [CrossRef]

50. Zhang, B.-H.; Shen, C.-A.; Zhu, B.-W.; An, H.-Y.; Zheng, B.; Xu, S.-B.; Sun, J.-C.; Sun, P.-C.; Zhang, W.; Wang, J.; et al. Insight into miRNAs related with glucometabolic disorder. Biomed. Pharmacother. 2019, 111, 657-665. [CrossRef]

51. Huang, Y.; Yan, Y.; Xv, W.; Qian, G.; Li, C.; Zou, H.; Li, Y. A New Insight into the Roles of MiRNAs in Metabolic Syndrome. BioMed Res. Int. 2018, 2018, 1-15. [CrossRef]

52. Mori, M.A.; Ludwig, R.G.; Garcia-Martin, R.; Brandão, B.B.; Kahn, C.R. Extracellular miRNAs: From Biomarkers to Mediators of Physiology and Disease. Cell Metab. 2019, 30, 656-673. [CrossRef]

53. Bao, P.-P.; Zheng, Y.; Nechuta, S.; Gu, K.; Cai, H.; Peng, P.; Shu, X.-O.; Lu, W. Exercise after diagnosis and metabolic syndrome among breast cancer survivors: A report from the Shanghai Breast Cancer Survival Study. Cancer Causes Control. 2013, 24, 1747-1756. [CrossRef] [PubMed]

54. Zhou, J.; Zheng, Q.; Xu, T.; Liao, D.; Zhang, Y.; Yang, S.; Hu, J. Associations Between Physical Activity-related miRNAs and Metabolic Syndrome. Horm. Metab. Res. 2013, 46, 201-205. [CrossRef]

55. Westphal, J.G.; Schulze, P.C. Exercise training in cancer related cardiomyopathy. J. Thorac. Dis. 2018, 10, S4391-S4399. [CrossRef] [PubMed]

56. McCarthy, J.J. The MyomiR Network in Skeletal Muscle Plasticity. Exerc. Sport Sci. Rev. 2011, 39, 150-154. [CrossRef]

57. Kirby, T.J.; McCarthy, J.J. MicroRNAs in skeletal muscle biology and exercise adaptation. Free. Radic. Biol. Med. 2013, 64, 95-105. [CrossRef] [PubMed]

58. Pereira, J.D.; Tosatti, J.A.G.; Simões, R.; Luizon, M.; Gomes, K.B.; Alves, M.T. microRNAs associated to anthracycline-induced cardiotoxicity in women with breast cancer: A systematic review and pathway analysis. Biomed. Pharmacother. 2020, 131, 110709. [CrossRef] [PubMed]

59. Ruggeri, C.; Gioffré, S.; Achilli, F.; Colombo, G.; D’Alessandra, Y. Role of microRNAs in doxorubicin-induced cardiotoxicity: An overview of preclinical models and cancer patients. Heart Fail. Rev. 2018, 23, 109-122. [CrossRef]

60. Horie, T.; Ono, K.; Nishi, H.; Nagao, K.; Kinoshita, M.; Watanabe, S.; Kuwabara, Y.; Nakashima, Y.; Takanabe-Mori, R.; Nishi, E.; et al. Acute doxorubicin cardiotoxicity is associated with miR-146a-induced inhibition of the neuregulin-ErbB pathway. Cardiovasc. Res. 2010, 87, 656-664. [CrossRef] [PubMed]

61. Rigaud, V.; Ferreira, L.R.; Ayub-Ferreira, S.M.; Ávila, M.S.; Brandão, S.M.; Cruz, F.D.; Santos, M.; Cruz, C.B.; Alves, M.S.; Issa, V.S.; et al. Circulating miR-1 as a potential biomarker of doxorubicin-induced cardiotoxicity in breast cancer patients. Oncotarget 2017, 8, 6994-7002. [CrossRef]

62. Leger, K.J.; Leonard, D.; Nielson, D.; de Lemos, J.A.; Mammen, P.P.; Winick, N.J. Circulating microRNAs: Potential Markers of Cardiotoxicity in Children and Young Adults Treated with Anthracycline Chemotherapy. J. Am. Hear. Assoc. 2017, 6(4), e004653. [CrossRef]

63. Denham, J.; Prestes, P.R. Muscle-Enriched MicroRNAs Isolated from Whole Blood Are Regulated by Exercise and Are Potential Biomarkers of Cardiorespiratory Fitness. Front. Genet. 2016, 7, 196. [CrossRef]

64. Kulyté, A.; Lorente-Cebrián, S.; Gao, H.; Mejhert, N.; Agustsson, T.; Arner, P.; Rydén, M.; Dahlman, I. MicroRNA profiling links miR-378 to enhanced adipocyte lipolysis in human cancer cachexia. Am. J. Physiol. Metab. 2014, 306, 267-274. [CrossRef]

65. Fearon, K.; Strasser, F.; Anker, S.D.; Bosaeus, I.; Bruera, E.; Fainsinger, R.L.; Jatoi, A.; Loprinzi, C.; MacDonald, N.; Mantovani, G.; et al. Definition and classification of cancer cachexia: An international consensus. Lancet Oncol. 2011, 12, 489-495. [CrossRef]

66. Zhou, X.; Wang, J.L.; Lu, J.; Song, Y.; Kwak, K.S.; Jiao, Q.; Rosenfeld, R.; Chen, Q.; Boone, T.; Simonet, W.S.; et al. Reversal of Cancer Cachexia and Muscle Wasting by ActRIIB Antagonism Leads to Prolonged Survival. Cell 2010, 142, 531-543. [CrossRef] [PubMed]

67. Narasimhan, A.; Ghosh, S.; Stretch, C.; Greiner, R.; Bathe, O.F.; Baracos, V.; Damaraju, S. Small RNAome profiling from human skeletal muscle: Novel miRNAs and their targets associated with cancer cachexia. J. Cachex-Sarcopenia Muscle 2017, 8, 405-416. [CrossRef] [PubMed]

68. Belloum, Y.; Rannou-Bekono, F.; Favier, F.B. Cancer-induced cardiac cachexia: Pathogenesis and impact of physical activity (Review). Oncol. Rep. 2017, 37, 2543-2552. [CrossRef]

69. Wardle, S.L.; Bailey, M.E.S.; Kilikevicius, A.; Malkova, D.; Wilson, R.H.; Venckunas, T.; Moran, C.N. Plasma MicroRNA Levels Differ between Endurance and Strength Athletes. PLoS ONE 2015, 10, e0122107. [CrossRef] [PubMed]

70. Massie, M.J. Prevalence of Depression in Patients with Cancer. J. Natl. Cancer Inst. Monogr. 2004, 32, 57-71. [CrossRef] 
71. Tsaras, K.; Papathanasiou, I.V.; Mitsi, D.; Veneti, A.; Kelesi, M.; Zyga, S.; Fradelos, E.C. Assessment of Depression and Anxiety in Breast Cancer Patients: Prevalence and Associated Factors. Asian Pac. J. Cancer Prev. APJCP 2018, 19, 1661-1669. [CrossRef]

72. Stark, D.; Kiely, M.; Smith, A.D.; Velikova, G.; House, A.; Selby, P.J. Anxiety Disorders in Cancer Patients: Their Nature, Associations, and Relation to Quality of Life. J. Clin. Oncol. Off. J. Am. Soc. Clin. Oncol. 2002, 20, 3137-3148. [CrossRef]

73. Bukberg, J.; Penman, D.; Holland, J.C. Depression in Hospitalized Cancer Patients. Psychosom. Med. 1984, 46, 199-212. [CrossRef] [PubMed]

74. Satin, J.R.; Linden, W.; Phillips, M.J. Depression as a predictor of disease progression and mortality in cancer patients: A meta-analysis. Cancer 2009, 115, 5349-5361. [CrossRef]

75. Chan, C.M.H.; Ahmad, W.A.W.; Yusof, M.M.; Ho, G.-F.; Krupat, E. Effects of depression and anxiety on mortality in a mixed cancer group: A longitudinal approach using standardised diagnostic interviews. Psycho-Oncol. 2015, 24, 718-725. [CrossRef] [PubMed]

76. Gururajan, A.; Clarke, G.; Dinan, T.; Cryan, J.F. Molecular biomarkers of depression. Neurosci. Biobehav. Rev. 2016, 64, 101-133. [CrossRef]

77. Malan-Müller, S.; Hemmings, S.M.J.; Seedat, S. Big Effects of Small RNAs: A Review of MicroRNAs in Anxiety. Mol. Neurobiol. 2012, 47, 726-739. [CrossRef]

78. Jin, J.; Kim, S.-N.; Liu, X.; Zhang, H.; Zhang, C.; Seo, J.-S.; Kim, Y.; Sun, T. miR-17-92 Cluster Regulates Adult Hippocampal Neurogenesis, Anxiety, and Depression. Cell Rep. 2016, 16, 1653-1663. [CrossRef] [PubMed]

79. Courneya, K.S.; McKenzie, D.C.; Gelmon, K.; Mackey, J.R.; Reid, R.D.; Yasui, Y.; Friedenreich, C.; Forbes, C.; Trinh, L.; Jespersen, D.; et al. A Multicenter Randomized Trial of the Effects of Exercise Dose and Type on Psychosocial Distress in Breast Cancer Patients Undergoing Chemotherapy. Cancer Epidemiol. Biomark. Prev. 2014, 23, 857-864. [CrossRef] [PubMed]

80. Mehnert, A.; Veers, S.; Howaldt, D.; Braumann, K.-M.; Koch, U.; Schulz, K.-H. Effects of a Physical Exercise Rehabilitation Group Program on Anxiety, Depression, Body Image, and Health-Related Quality of Life among Breast Cancer Patients. Onkologie 2011, 34, 248-253. [CrossRef] [PubMed]

81. Liu, W.; Xue, X.; Xia, J.; Liu, J.; Qi, Z. Swimming exercise reverses CUMS-induced changes in depression-like behaviors and hippocampal plasticity-related proteins. J. Affect. Disord. 2018, 227, 126-135. [CrossRef]

82. Gomes, J.L.P.; Fernandes, T.; Soci, U.P.R.; Silveira, A.C.; Barretti, D.L.M.; Negrão, C.E.; Oliveira, E.M. Obesity Downregulates MicroRNA-126 Inducing Capillary Rarefaction in Skeletal Muscle: Effects of Aerobic Exercise Training. Oxidative Med. Cell. Longev. 2017, 2017, 1-9. [CrossRef]

83. Ghorbanzadeh, V.; Mohammadi, M.; Dariushnejad, H.; Abhari, A.; Chodari, L.; Mohaddes, G. Cardioprotective Effect of Crocin Combined with Voluntary Exercise in Rat: Role of Mir-126 and Mir-210 in Heart Angiogenesis. Arq. Bras. de Cardiol. 2017, 109, 54-62. [CrossRef]

84. Zhang, L.; Ouyang, P.; He, G.; Wang, X.; Song, D.; Yang, Y.; He, X. Exosomes from microRNA-126 overexpressing mesenchymal stem cells promote angiogenesis by targeting the PIK3R2-mediated PI3K/Akt signalling pathway. J. Cell. Mol. Med. 2021, 25, 2148-2162. [CrossRef] [PubMed]

85. Junior, G.S.M.; Souza, V.C.; Machado-Silva, W.; Henriques, A.D.; Alves, A.M.; Morais, D.B.; Nóbrega, O.T.; Brito, C.; Silva, R.J.D.S. Clinical Interventions in Aging Dovepress Acute strength training promotes responses in whole blood circulating levels of miR-146a among older adults with type 2 diabetes mellitus. Clin. Interv. Aging 2017, 12, 1443. [CrossRef] [PubMed]

86. Roos, J.; Dahlhaus, M.; Funcke, J.-B.; Kustermann, M.; Strauss, G.; Halbgebauer, D.; Boldrin, E.; Holzmann, K.; Möller, P.; Trojanowski, B.M.; et al. miR-146a regulates insulin sensitivity via NPR3. Cell. Mol. Life Sci. 2021, 78, 2987-3003. [CrossRef]

87. Jiang, Y.; Wang, C.-Y.; Liu, L.; Guo, S.-H.; Zhang, L.; Cai, J.-H. Peripheral blood miRNAs as a biomarker for chronic cardiovascular diseases. Sci. Rep. 2014, 4, 5026. [CrossRef] [PubMed]

88. Fathi, M.; Gharakhanlou, R.; Rezaei, R. The Changes of Heart miR-1 and miR-133 Expressions following Physiological Hypertrophy Due to Endurance Training. Cell J. 2020, 22 (Suppl. 1), 133-140.

89. Mooren, F.C.; Viereck, J.; Krüger, K.; Thum, T. Circulating micrornas as potential biomarkers of aerobic exercise capacity. Am. J. Physiol. Circ. Physiol. 2014, 306, H557-H563. [CrossRef] [PubMed]

90. Nielsen, S.; Scheele, C.; Yfanti, C.; Åkerström, T.; Nielsen, A.R.; Pedersen, B.K.; Laye, M. Muscle specific microRNAs are regulated by endurance exercise in human skeletal muscle. J. Physiol. 2010, 588, 4029-4037. [CrossRef] [PubMed]

91. Tony, H.; Yu, K.; Qiutang, Z. MicroRNA-208a Silencing Attenuates Doxorubicin Induced Myocyte Apoptosis and Cardiac Dysfunction. Oxidative Med. Cell. Longev. 2015, 2015, 1-6. [CrossRef]

92. Song, W.; Liang, Q.; Cai, M.; Tian, Z. HIF-1 $\alpha$-induced up-regulation of microRNA-126 contributes to the effectiveness of exercise training on myocardial angiogenesis in myocardial infarction rats. J. Cell. Mol. Med. 2020, 24, 12970-12979. [CrossRef]

93. Riedel, S.; Radzanowski, S.; Bowen, T.S.; Werner, S.; Erbs, S.; Schuler, G.; Adams, V. Exercise training improves high-density lipoprotein-mediated transcription of proangiogenic microRNA in endothelial cells. Eur. J. Prev. Cardiol. 2015, 22, 899-903. [CrossRef]

94. Dai, B.; Li, H.; Fan, J.; Zhao, Y.; Yin, Z.; Nie, X.; Wang, D.W.; Chen, C. MiR-21 protected against diabetic cardiomyopathy induced diastolic dysfunction by targeting gelsolin. Cardiovasc. Diabetol. 2018, 17, 123. [CrossRef] [PubMed]

95. Wang, Y.; Zhang, J.; Fu, M.; Wang, J.; Cui, X.; Song, Y.; Han, X.; Liu, Y.; Zhou, J.; Ge, J. Qiliqiangxin Prescription Promotes Angiogenesis of Hypoxic Primary Rat Cardiac Microvascular Endothelial Cells via Regulating miR-21 Signaling. Curr. Pharm. Des. 2021, 27, 2966-2974. [CrossRef] [PubMed] 
96. He, J.; Lu, Y.; Song, X.; Gong, X.; Li, Y. Inhibition of microRNA-146a attenuated heart failure in myocardial infarction rats. Biosci. Rep. 2019, 39, BSR20191732. [CrossRef] [PubMed]

97. Li, Y.; Yao, M.; Zhou, Q.; Cheng, Y.; Che, L.; Xu, J.; Xiao, J.; Shen, Z.; Bei, Y. Dynamic Regulation of Circulating microRNAs During Acute Exercise and Long-Term Exercise Training in Basketball Athletes. Front. Physiol. 2018, 9, 282. [CrossRef]

98. Baggish, A.L.; Hale, A.; Weiner, R.B.; Lewis, G.D.; Systrom, D.; Wang, F.; Wang, T.; Chan, S.Y. Dynamic regulation of circulating microRNA during acute exhaustive exercise and sustained aerobic exercise training. J. Physiol. 2011, 589, 3983-3994. [CrossRef]

99. Bye, A.; Røsjø, H.; Aspenes, S.T.; Condorelli, G.; Omland, T.; Wisløff, U. Circulating MicroRNAs and Aerobic Fitness-The HUNT-Study. PLoS ONE 2013, 8, e57496. [CrossRef]

100. Zhang, S.; Wang, Y.; Wang, Y.; Peng, J.; Yuan, C.; Zhou, L.; Xu, S.; Lin, Y.; Du, Y.; Yang, F.; et al. Serum miR-222-3p as a Double-Edged Sword in Predicting Efficacy and Trastuzumab-Induced Cardiotoxicity for HER2-Positive Breast Cancer Patients Receiving Neoadjuvant Target Therapy. Front. Oncol. 2020, 10, 631. [CrossRef]

101. Schmitz, B.; Rolfes, F.; Schelleckes, K.; Mewes, M.; Thorwesten, L.; Krüger, M.; Klose, A.; Brand, S.-M. Longer Work/Rest Intervals During High-Intensity Interval Training (HIIT) Lead to Elevated Levels of miR-222 and miR-29c. Front. Physiol. 2018,9 , 395. [CrossRef] [PubMed]

102. Liu, X.; Xiao, J.; Zhu, H.; Wei, X.; Platt, C.; Damilano, F.; Xiao, C.; Bezzerides, V.; Boström, P.; Che, L.; et al. miR-222 Is Necessary for Exercise-Induced Cardiac Growth and Protects against Pathological Cardiac Remodeling. Cell Metab. 2015, 21, 584-595. [CrossRef]

103. Le Sage, C.; Nagel, R.; Egan, D.A.; Schrier, M.; Mesman, E.; Mangiola, A.; Anile, C.; Maira, G.; Mercatelli, N.; Ciafrè, S.A.; et al. Regulation of the p27Kip1 tumor suppressor by miR-221 and miR-222 promotes cancer cell proliferation. EMBO J. 2007, 26, 3699-3708. [CrossRef]

104. Eissa, M.G.; Artlett, C.M. The MicroRNA miR-155 Is Essential in Fibrosis. Non-Coding RNA 2019, 5, 23. [CrossRef] [PubMed]

105. Wang, D.; Liu, Z.; Yan, Z.; Liang, X.; Liu, X.; Liu, Y.; Wang, P.; Bai, C.; Gu, Y.; Zhou, P.-K. MiRNA-155-5p inhibits epithelium-tomesenchymal transition (EMT) by targeting GSK-3 $\beta$ during radiation-induced pulmonary fibrosis. Arch. Biochem. Biophys. 2021, 697, 108699. [CrossRef]

106. Kurowska-Stolarska, M.; Hasoo, M.K.; Welsh, D.J.; Stewart, L.; McIntyre, D.; Morton, B.E.; Johnstone, S.; Miller, A.M.; Asquith, D.L.; Millar, N.L.; et al. The role of microRNA-155/liver X receptor pathway in experimental and idiopathic pulmonary fibrosis. J. Allergy Clin. Immunol. 2017, 139, 1946-1956. [CrossRef]

107. Paula, S.M.; Fernandes, T.; Couto, G.K.; Jordão, M.T.; Oliveira, E.M.; Michelini, L.C.; Rossoni, L.V. Molecular Pathways Involved in Aerobic Exercise Training Enhance Vascular Relaxation. Med. Sci. Sports Exerc. 2020, 52, 2117-2126. [CrossRef]

108. Barber, J.L.; Zellars, K.N.; Barringhaus, K.G.; Bouchard, C.; Spinale, F.G.; Sarzynski, M.A. The Effects of Regular Exercise on Circulating Cardiovascular-related MicroRNAs. Sci. Rep. 2019, 9, 7527. [CrossRef]

109. Fu, J.; Peng, C.; Wang, W.; Jin, H.; Tang, Q.; Wei, X. Let-7g is involved in doxorubicin induced myocardial injury. Environ. Toxicol. Pharmacol. 2012, 33, 312-317. [CrossRef]

110. Wang, D.; Wang, Y.; Ma, J.; Wang, W.; Sun, B.; Zheng, T.; Wei, M.; Sun, Y. MicroRNA-20a participates in the aerobic exercise-based prevention of coronary artery disease by targeting PTEN. Biomed. Pharmacother. 2017, 95, 756-763. [CrossRef] [PubMed]

111. Soares, R.J.R.; Cagnin, S.; Chemello, F.; Silvestrin, M.; Musaro, A.; De Pitta, C.; Lanfranchi, G.; Sandri, M. Involvement of MicroRNAs in the Regulation of Muscle Wasting during Catabolic Conditions. J. Biol. Chem. 2014, 289, 21909-21925. [CrossRef] [PubMed]

112. He, W.A.; Calore, F.; Londhe, P.; Canella, A.; Guttridge, D.C.; Croce, C.M. Microvesicles containing miRNAs promote muscle cell death in cancer cachexia via TLR7. Proc. Natl. Acad. Sci. USA 2014, 111, 4525-4529. [CrossRef]

113. Okugawa, Y.; Yao, L.; Toiyama, Y.; Yamamoto, A.; Shigemori, T.; Yin, C.; Omura, Y.; Ide, S.; Kitajima, T.; Shimura, T.; et al. Prognostic impact of sarcopenia and its correlation with circulating miR-21 in colorectal cancer patients. Oncol. Rep. 2018, 39, 1555-1564. [CrossRef]

114. Borja-Gonzalez, M.; Casas-Martinez, J.C.; McDonagh, B.; Goljanek-Whysall, K. Inflamma-miR-21 Negatively Regulates Myogenesis during Ageing. Antioxidants 2020, 9, 345. [CrossRef]

115. Chen, J.-F.; Mandel, E.M.; Thomson, J.M.; Wu, Q.; E Callis, T.; Hammond, S.M.; Conlon, F.L.; Wang, D.-Z. The Role of MicroRNA-1 and MicroRNA-133 in Skeletal Muscle Proliferation and Differentiation. Nat. Genet. 2005, 38, 228-233. [CrossRef] [PubMed]

116. Huang, M.; Xu, H.; Xie, S.-J.; Zhou, H.; Qu, L.-H. Insulin-Like Growth Factor-1 Receptor Is Regulated by microRNA-133 during Skeletal Myogenesis. PLoS ONE 2011, 6, e29173. [CrossRef]

117. Drummond, M.J.; McCarthy, J.J.; Fry, C.S.; Esser, K.A.; Rasmussen, B.B. Aging differentially affects human skeletal muscle microRNA expression at rest and after an anabolic stimulus of resistance exercise and essential amino acids. Am. J. Physiol. Endocrinol. Metab. 2008, 295, E1333-E1340. [CrossRef] [PubMed]

118. Nie, Y.; Sato, Y.; Wang, C.; Yue, F.; Kuang, S.; Gavin, T.P. Impaired exercise tolerance, mitochondrial biogenesis, and muscle fiber maintenance in miR-133a-deficient mice. FASEB J. 2016, 30, 3745-3758. [CrossRef] [PubMed]

119. Bocchio-Chiavetto, L.; Maffioletti, E.; Bettinsoli, P.; Giovannini, C.; Bignotti, S.; Tardito, D.; Corrada, D.; Milanesi, L.; Gennarelli, M. Blood microRNA changes in depressed patients during antidepressant treatment. Eur. Neuropsychopharmacol. 2013, $23,602-611$. [CrossRef] [PubMed]

120. Wei, Y.B.; Liu, J.J.; Villaescusa, J.C.; Åberg, E.; Brené, S.; Wegener, G.; A Mathé, A.; Lavebratt, C. Elevation of Il6 is associated with disturbed let-7 biogenesis in a genetic model of depression. Transl. Psychiatry 2016, 6, e869. [CrossRef] 
121. Gururajan, A.; Naughton, M.E.; Scott, K.A.; O'Connor, R.M.; Moloney, G.; Clarke, G.; Dowling, J.; Walsh, A.; Ismail, F.; Shorten, G.; et al. MicroRNAs as biomarkers for major depression: A role for let-7b and let-7c. Transl. Psychiatry 2016, 6, e862. [CrossRef]

122. Hung, Y.-Y.; Wu, M.-K.; Tsai, M.-C.; Huang, Y.-L.; Kang, H.-Y. Aberrant Expression of Intracellular let-7e, miR-146a, and miR-155 Correlates with Severity of Depression in Patients with Major Depressive Disorder and Is Ameliorated after Antidepressant Treatment. Cells 2019, 8, 647. [CrossRef]

123. Li, Y.-J.; Xu, M.; Gao, Z.-H.; Wang, Y.-Q.; Yue, Z.; Zhang, Y.-X.; Li, X.-X.; Zhang, C.; Xie, S.-Y.; Wang, P.-Y. Alterations of Serum Levels of BDNF-Related miRNAs in Patients with Depression. PLoS ONE 2013, 8, e63648. [CrossRef]

124. Tong, L.; Li, M.-D.; Nie, P.-Y.; Chen, Y.; Chen, Y.-L.; Ji, L.-L. miR-132 downregulation alleviates behavioral impairment of rats exposed to single prolonged stress, reduces the level of apoptosis in PFC, and upregulates the expression of MeCP2 and BDNF. Neurobiol. Stress 2021, 14, 100311. [CrossRef] [PubMed]

125. Zhu, J.; Chen, Z.; Tian, J.; Meng, Z.; Ju, M.; Wu, G.; Tian, Z. miR-34b attenuates trauma-induced anxiety-like behavior by targeting CRHR1. Int. J. Mol. Med. 2017, 40, 90-100. [CrossRef] [PubMed]

126. Sun, N.; Yang, C.; He, X.; Liu, Z.; Liu, S.; Li, X.; Wang, Y.; Jin, R.; Zhang, K. Impact of Expression and Genetic Variation of microRNA-34b/c on Cognitive Dysfunction in Patients with Major Depressive Disorder. Neuropsychiatr. Dis. Treat. 2020, 16, 1543-1554. [CrossRef] [PubMed]

127. Ramzan, F.; D'Souza, R.F.; Durainayagam, B.R.; Milan, A.M.; Markworth, J.F.; Miranda-Soberanis, V.; Sequeira, I.R.; Roy, N.C.; Poppitt, S.D.; Mitchell, C.J.; et al. Circulatory miRNA biomarkers of metabolic syndrome. Acta Diabetol. 2020, 57, 203-214. [CrossRef] [PubMed] 